\title{
Spatial aggregations in annual wild plant communities: Competition, Performance, and Coexistence
}

\author{
Dissertation \\ zur Erlangung des Doktorgrades \\ der Fakultät für Agrarwissenschaften \\ der Georg-August-Universität Göttingen \\ vorgelegt von \\ Birte Eleen Waßmuth \\ geboren in Göttingen
}

Göttingen, November 2008 
D 7

1. Referent: Prof. Dr. Teja Tscharntke

2. Korreferent: PD Dr. Peter Stoll

Tag der mündlichen Prüfung: 06.11.2008 


\section{Table of contents}

General introduction: Spatial aggregations in annual wild plant communities:

Competition, Performance, and Coexistence 1

Introduction 2

Chapter outline and Hypotheses 3

Study species and Design $\quad 4$

Results and Conclusion $\quad 6$

References $\quad 8$

Spatial aggregation facilitates coexistence and diversity of wild plant species in field margins

$\begin{array}{ll}\text { Abstract } & 12\end{array}$

Introduction 13

Material and Methods $\quad 14$

Results 16

Discussion 23

Acknowledgements $\quad 25$

References $\quad 26$

Increasing the scale of intraspecific aggregation facilitates competitively weak plants

$\begin{array}{ll}\text { Abstract } & 31\end{array}$

Introduction $\quad 32$

Materials and Methods 33

Results 37

Discussion $\quad 42$

Acknowledgements $\quad 44$

References $\quad 45$

Scale-dependence of intra- and interspecific interactions of annual plants $\quad 48$

$\begin{array}{ll}\text { Abstract } & 49\end{array}$

Introduction $\quad 50$

Materials and Methods $\quad 51$

Results 53

Discussion $\quad 54$

References $\quad 56$ 
Sowing competitively weak arable wild plant species with intraspecific aggregation helps to enhance coexistence and biodiversity

$\begin{array}{ll}\text { Abstract } & 59 \\ \text { Introduction } & 60 \\ \text { Materials and Methods } & 61 \\ \text { Results } & 62 \\ \text { Discussion } & 66 \\ \text { Acknowledgements } & 67 \\ \text { References } & 68\end{array}$

$\begin{array}{ll}\text { Summary } & 71\end{array}$

Zusammenfassung $\quad 73$

Danksagung $\quad 75$

$\begin{array}{ll}\text { Publications } & 76\end{array}$

$\begin{array}{ll}\text { Curriculum Vitae } & 77\end{array}$ 


\section{Chapter 1}

General introduction:

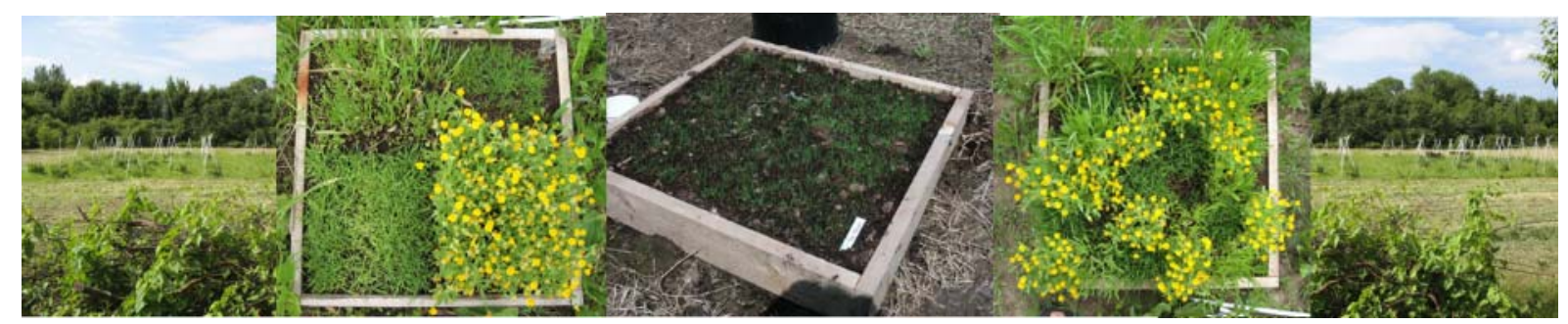

Spatial aggregations

in annual wild plant communities:

Competition, Performance, and Coexistence 


\section{Introduction}

Biodiversity is a current topic in politics and of great public interest. It is widely discussed how to maintain biodiversity world wide. Plant diversity in agricultural habitats has been declining in the last decades due to the change and intensification of agricultural practices (Hofmeister and Garve 1986; Stoate et al. 2001). To counteract this development agrienvironment schemes such as annually sown field margin strips were set up in Europe (Stoate et al. 2001; Kleijn et al. 2006), but establishing species-rich margin strips is not as simple. A local species pool is widely missing (Denys et al. 1997; Kleijn et al. 1998; Anderlik-Wesinger et al. 1999; Westbury et al. 2008) due to intensive fertilizer and herbicide application. Even sowing species rich seed mixtures may result in species poor plant communities consisting of few common and competitively strong species (Denys et al. 1997; Kleijn et al. 1998; Denys and Tscharntke 2002; De Cauwer et al. 2006; Lepš et al. 2007; although see Critchley and Fowbert 2000). In the present, work we addressed the problem of species poor sown margins and investigated whether intraspecific aggregation of competitively weak species can enable coexistence and thereby increase biodiversity in agricultural habitats.

Plant competition is known to determine local plant communities (Aerts 1999; Barot 2004; Brose and Tielbörger 2005). Individuals are influenced by the size, distance, and identity of neighbouring plants (Purves and Law 2002; Barot 2004; Bachmann et al. 2005; Berger et al. 2006). Competition can be differentiated into intra- and interspecific competition, but only few studies investigated intra- and interspecific competition between annuals (Stoll and Prati 2001; Fridley 2003; Monzeglio and Stoll 2005; Mokany et al. 2008), while perennials and trees have been more often subject to competition studies (Martens et al. 1997; Smith et al. 1999; Goreaud et al. 2002; Bokenstrand et al. 2004; Bachmann et al. 2005; Lenssen et al. 2005). Intraspecific competition appeared to be relatively stronger than interspecific competition (Martens et al. 1997; Freckleton and Watkinson 2000; Jumpponen et al. 2005), thus allowing coexistence (Chesson 2000; Amarasekare 2003). An intraspecifically aggregated seeding pattern reduces the incidents with heterospecific neighbours. Hence, most individuals experience only intraspecific competition and only few individuals at the edges face intra- and interspecific competition. Weak competitors will be enhanced by reduced interspecific competition (De Boeck et al. 2006), and the rate of displacement can be slowed down (Levine and Murrel 2003; but see Chesson and Neuhauser 2002). However, the knowledge at which spatial scale competition influences plant performance is limited (Damgaard 2004). In this work, we studied not only the effect 
of intraspecific aggregation versus random dispersal but established several scales of intraspecific aggregation in two different experiments.

Additionally, the selection of species is important for the success of species rich sowings. Grass species appeared to be more competitive than forbs (Pywell et al. 2003; Critchley et al. 2006; Lanta and Lepš 2007), but margins sown with a high percentage of grass species are often less diverse (Eggenschwiler et al. 2004). Forbs are harder to establish (Sheley and Half 2006; Weigelt et al. 2007) and are therefore often missing in seed mixtures. However, plant performance and competitiveness may change depending on the identity of competing species (Hooper 1998; Hooper and Dukes 2004). Therefore, we established several mixtures of grasses, forbs, and legumes in different species combinations to study how competition between different functional groups influences plant performance.

Environmental variation is another important driver of competition and species coexistence. In environments with a low nutrient availability plants compete mainly for nutrients. A high nutrient availability increases the intensity of competition, since plants compete not only for nutrients, but as well for light and space (Lanta and Lepš 2007). The more nutrients, the higher is the extinction risk especially for competitively inferior species (Lepš 1999). We established different seed mixtures and studied whether legumes enhance the productivity of different species in mixtures, and whether the performance of the legumes can be enhanced by intraspecific aggregation despite the high nutrient level.

\section{Chapter outline and Hypotheses}

In the present work, we investigated whether a certain spatial seeding pattern, namely intraspecific aggregation, enables competitively weak species to establish and to propagate. Moreover, we studied whether the effect of intraspecific aggregation will occur or even increase at different spatial scales, species combinations, and nutrient regimes. We focussed on annual wild plant species of arable habitats and varied the species mixtures by testing different numbers of species (Chapter 2 and 5), and by cultivating grasses, forbs and legumes in different species combinations (Chapter 3). Additionally, two nutrient levels were set up (Chapter 3). We studied the effect of increasing scales of intraspecific aggregation in a field experiment (Chapter 3) and in a small scale pot experiment (Chapter 4). In the last chapter, we present an experiment using forb species of a commercially available seed mixture. We investigated the competitive interactions between six study species in various mixtures consisting of up to twelve species (Chapter 5). 
Our main hypothesis was that (i) intraspecific aggregation enhances the performance of competitively weak plant species and that (ii) increasing the scale of intraspecific aggregation will pronounce this effect by reducing interspecific competition further. We hypothesized that the positive effect will be pronounced when (interspecific) competition increases. Hence, (iii) intraspecific aggregation will have a positive effect for competitively weak species especially in species-rich mixtures and (iv) at a high nutrient level. Furthermore, we expected that (v) grass and forb species will benefit from the legume species in seed mixtures of species belonging to different functional groups.

\section{Study species and Design}

We studied a variety of arable wild plant species (Table 1.1), which are boundary species and/or are found in seed mixtures for margin and flowering strips. All species were annuals, except the legumes Melilotus officinalis (biennial) and Trifolium campestre (facultative biennial).

We established randomly dispersed and intraspecifically aggregated plots (Fig. 1.1), to be able to observe the effect of the shift from intra- and interspecific competition towards solely intraspecific competition. The field experiments and the commercial seed mixture were sown, while in the third experiment seedlings were transplanted into pots. The overall seeding density (within each experiment) was similar irrespective of spatial patterns. We measured plant performance in terms of biomass per individual, biomass per $\mathrm{m}^{2}$, number of harvested individuals, and numbers of flowers per individual. Moreover, we calculated the competitive ability of a species to be able to distinguish between competitively weak and competitively strong species. 
Table 1.1 Study species and number of species in mixtures.

\begin{tabular}{|c|c|c|c|c|}
\hline \multirow[b]{2}{*}{ Plant species } & \multicolumn{2}{|c|}{ Field experiments } & \multicolumn{2}{|c|}{ Pot experiments } \\
\hline & Chapter 2 & Chapter 3 & Chapter 4 & Chapter 5 \\
\hline Agrostemma githago & & & & $\mathrm{x}$ \\
\hline Anthemis arvensis & & & & $\mathrm{x}$ \\
\hline Bromus mollis & $\mathrm{x}$ & $\mathrm{x}$ & & \\
\hline Calendula arvensis & $\mathrm{x}$ & $\mathrm{x}$ & & $\mathrm{x}$ \\
\hline Centaurea cyanus & $\mathrm{x}$ & $\mathrm{x}$ & $\mathrm{x}$ & $\mathrm{x}$ \\
\hline Chrysanthemum segetum & & & & $\mathrm{x}$ \\
\hline Consolida regalis & & & & $\mathrm{x}$ \\
\hline Legousia speculum-veneris & & & & $\mathrm{x}$ \\
\hline Matricaria recutita & & & & $\mathrm{x}$ \\
\hline Medicago lupulina & $\mathrm{x}$ & $\mathrm{x}$ & & \\
\hline Melilotus officinalis & $\mathrm{x}$ & & & \\
\hline Myosotis arvensis & & & & $\mathrm{x}$ \\
\hline Papaver rhoeas & & & & $\mathrm{x}$ \\
\hline Poa апnиа & $\mathrm{x}$ & $\mathrm{x}$ & & \\
\hline Silene noctiflora & & & & $\mathrm{x}$ \\
\hline Trifolium campestre & & $\mathrm{x}$ & & \\
\hline Viola arvensis & & & $\mathrm{x}$ & $\mathrm{x}$ \\
\hline Number of species in mixtures & 6 & 6 & 2 & 12 \\
\hline
\end{tabular}
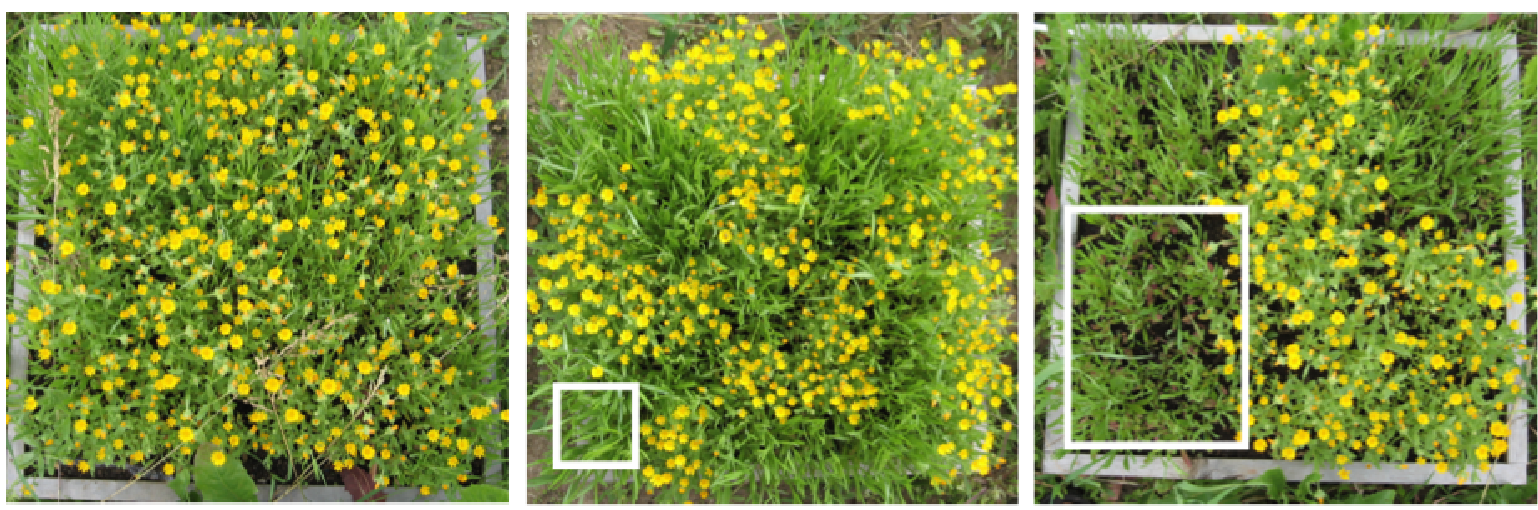

Figure 1.1 Spatial seeding patterns: random dispersal (left), small scale intraspecific aggregation (center), and large scale intraspecific aggregation (right). 


\section{Results and Conclusion}

Intraspecific aggregation had a positive effect on competitively weak species. More precisely, the grass and legume species in the field experiments and the competitively weak species in the pot experiments benefited from being exposed to only intraspecific competition. Their performance in terms of biomass per individual and biomass per $\mathrm{m}^{2}$ was largely enhanced. Additionally, intraspecific aggregation had an overall positive effect on the number of harvested individuals, irrespective of the identity and competitive ability of the species.

Increasing the scale of intraspecific aggregation led to species specific results. Both legume species yielded more biomass in the large scale aggregations. Of the two grass species Bromus mollis and Poa annua, only the latter yielded more biomass, while the former produced less biomass in large scale aggregations. However, when the scale of intraspecific aggregation was increased in a small-scale pot experiment, the competitively weak species benefited only in terms of number of flowers from the larger scales of intraspecific aggregation.

The number of species in mixtures had a strong effect on the species ranked on the upper and lower end of the competitive hierarchy. The two competitively weakest species suffered from increased interspecific competition in multi-species mixtures, whereas the competitively strong species doubled their biomass production. Nevertheless, all species yielded fewer individuals in species-rich mixtures. The positive effect of intraspecific aggregation occurred especially in multi-species mixtures, where competition was increased. According to our hypothesis, biomass of the competitively weak species was higher when they were cultivated intraspecifically aggregated. All species, irrespective of species identity and ranking, benefited in terms of number of individuals from intraspecific aggregation in multi-species mixtures.

The functional group (e.g. grass, forb or legume species) of the competing species influenced plant performance as well. Grass species were positively affected by the presence of legumes, whereas the forb species did not respond. This result was surprising, since we expected all species to benefit from legumes in mixtures. The competitively weak legumes performed better in the only-legumes mixtures, as soon as grasses or forbs were present, legume biomass decreased due to increased interspecific competition. Contrary, the competitively strong forb species performed better in multi-species mixtures, while they were suppressed in the only-forbs mixtures. 
The nutrient level strongly influenced plant performance of all species. Grasses and forbs suffered from nutrient deficiency, yielding less biomass in nutrient poor plots, whereas the legume species were able to produce more biomass in nutrient poor plots than in nutrient rich plots. However, intraspecific aggregation increased legume performance in nutrient rich plots. Medicago lupulina yielded relatively more biomass in small and large scale aggregations compared to randomly dispersed plots. Thus, intraspecific aggregation enhances the performance of competitively weak species especially under highly competitive conditions.

In conclusion, we showed that competitively weak plant species can be enhanced by intraspecific aggregation. Competitively weak and therefore often rare plant species may establish and propagate when cultivated intraspecifically aggregated, thereby adding seeds to the local species pool. Hence, sowings with spatial seeding patterns can successfully contribute to conservation measures such as sown field margin strips by enabling the coexistence of species-rich plant communities. 


\section{References}

Aerts, R., 1999. Interspecific competition in natural plant communities: mechanisms, trade-offs and plant-soil feedbacks. Journal of Experimental Botany 50, 29-37.

Amarasekare, P., 2003. Competitive coexistence in spatially structured environments: a synthesis. Ecology Letters 6, 1109-1122.

Anderlik-Wesinger, G., Albrecht, H., Pfadenhauer, J., 1999. Spontaneous and directed vegetation development on newly established boundary structures. Aspects of Applied Biology 54, 283-290.

Barot, S., 2004. Mechanisms promoting plant coexistence: can all the proposed processes be reconciled. Oikos 106, 185-191.

Bachmann, U., Hensen, I., Partzsch, M., 2005. Is Campanula glomerata threatened by competition of expanding grasses? Plant Ecology 180, 257-265.

Berger, A.G., McDonald, A.J., Riha, S.J., 2006. Scaling plant size to below-ground zone of influence in annuals under contrasting competitive environments. Functional Ecology 20, 770-777.

Bokenstrand, A., Lagerlöf, J., Torstensson, P.R., 2004. Establishment of vegetation in broadened field boundaries in agricultural landscapes. Agriculture, Ecosystems and Environment 101, 21-29.

Brose, U., Tielbörger, K., 2005. Subtle differences in environmental stress along a flooding gradient affect the importance of interspecific competition in an annual plant community. Plant Ecology 178, 51-59.

Chesson, P., 2000. Mechanisms of maintenance of species diversity. Annual Review of Ecology and Systematics 31, 343-366.

Chesson, P., Neuhauser, C., 2002. Intraspecific aggregation and species coexistence. Trends in Ecology and Evolution 17, 210.

Critchley, C.N.R., Fowbert, J.A., 2000. Development of vegetation on set-aside land for up to nine years from a national perspective. Agriculture, Ecosystems and Environment 79, 159-174.

Critchley, C.N.R., Fowbert, J.A., Sherwood, A.J., 2006. The effects of annual cultivation on plant community composition of uncropped arable field boundary strips. Agriculture, Ecosystems and Environment 113, 196-205.

Damgaard, C., 2004. Inference from plant competition experiments: the effect of spatial covariance. Oikos 107, 225-230.

De Boeck, H.J., Nijs, I., Lemmens, C.M.H.M., Ceulemans, R., 2006. Underlying effects of spatial aggregation (clumping) in relationships between plant diversity and resource uptake. Oikos 113, 269-278.

De Cauwer, B., Reheul, D., D'hooghe, K., Nijs, I., Milbau, A., 2006. Disturbance effects on early succession of field margins along the shaded and unshaded side of a tree lane. Agriculture, Ecosystems and Environment 112, 78-86.

Denys, C., Thies, C., Fischer, R., Tscharntke, T., 1997. Die ökologische Bewertung von Ackerrandstreifen im integrierten Landbau. Mitteilungen der NNA 3, 2-11. 
Denys, C., Tscharntke, T., 2002. Plant-insect communities and predator-prey ratios in field margin strips, adjacent crop fields, and fallows. Oecologia 130, 315-324.

Eggenschwiler, L., Jacot, K.A., Edwards, P.J., 2004. Bedeutung von Samenmischungen und Schnitt für Bunt- und Rotationsbrachen. Natur und Landschaft 79. Jahrgang, 544-550.

Freckleton, R.P., Watkinson, A.R., 2000. On detecting and measuring competition in spatially structured plant communities. Ecology Letters 3, 423-432.

Fridley, J.D., 2003. Diversity effects on production in different light and fertility environments: an experiment with communities of annual plants. Journal of Ecology 91, 396-406.

Hofmeister, H., Garve, E., 1986. Lebensraum Acker. Pflanzen der Äcker und ihre Ökologie. Parey Verlag, Hamburg and Berlin.

Goreaud, F., Loreau, M., Millier, C., 2002. Spatial structure and survival of an inferior competitor: a theoretical model of neighbourhood competition in plants. Ecological Modelling 158, 1-19.

Hooper, D.U., 1998. The role of complementarity and competition in ecosystem responses to variation in plant diversity. Ecology 79, 704-719.

Hooper, D.U., Dukes, J.S., 2004. Overyielding among plant functional groups in a long-term experiment. Ecology Letters 7, 95-105.

Jumpponen, A., Mulder, C.P.H., Huss-Danell, K., Högberg, P., 2005. Winners and losers in herbaceous plant communities: insights from foliar carbon isotope composition in monocultures and mixtures. Journal of Ecology 93, 1136-1147.

Kleijn, D., Joenje, W., Le Cœur, D., Marshall, E.J.P., 1998. Similarities in vegetation development of newly established herbaceous strips along contrasting European field boundaries. Agriculture, Ecosystems and Environment 68, 13-26.

Kleijn, D., Baquero, R.A., Clough, Y., Diaz, M., De Esteban, J., Fernández, F., Gabriel, D., Herzog, F., Holzschuh, A., Jöhl, R., Knop, E., Kruess, A., Marshall, E.J.P., Steffan-Dewenter, I., Tscharntke, T., Verhulst, J., West, T.M., Yela, J.L., 2006. Mixed biodiversity benefits of agrienvironment schemes in five European countries. Ecology Letters 9, 243-254.

Lanta, V., Lepš, J., 2007. Effects of species and functional group richness on production in two fertility environments: an experiment with communities of perennial plants. Acta Oecologia 32, 93103.

Lenssen, J.P.M., Hershock, C., Speek, T., During, H.J., De Kroon, H., 2005. Experimental ramet aggregation in the clonal plant Agrostis stolonifera reduces its competitive ability. Ecology 86, 1358-1365.

Lepš, J., 1999. Nutrient status, disturbance and competition: an experimental test of relationships in a wet meadow. Journal of Vegetation Science 10, 219-230. 
Lepš, J., Doležal, J., Bezemer, T.M., Brown, V.K., Hedlund, K., Igual Arroyo, M., Jörgensen, H.B., Lawson, C.S., Mortimer, S.R., Peix Geldart, A., Rodríguez Barrueco, C., Santa Regina, I., Ŝmilauer, P., van der Putten, W.H., 2007. Long-term effectiveness of sowing high and low diversity seed mixtures to enhance plant community development on ex-arable fields. Applied Vegetation Science 10, 97-110.

Levine, J.M., Murrell, D.J., 2003. The community-level consequences of seed dispersal patterns. Annual Review of Ecology and Systematics 34, 549-574.

Martens, S.N., Breshears, D.D., Meyer, C.W., Barnes, F.J., 1997. Scales of above-ground and below-ground competition in a semi-arid woodland detected from spatial pattern. Journal of Vegetation Science 8, 655-664.

Mokany, K., Ash, J., Roxburgh, S., 2008. Effects of spatial aggregation on competition, complementarity and resource use. Austral Ecology 33, 261-270.

Monzeglio, U., Stoll, P., 2005. Spatial patterns and species performances in experimental plant communities. Oecologia 145, 619-628.

Purves, D.W., Law, R., 2002. Experimental derivation of functions relating growth of Arabidobsis thaliana to neighbour size and distance. Journal of Ecology 90, 882-894.

Pywell, R.F., Bullock, J.M., Roy, D.B., Warman, L., Walker, K.J., Rothery, P., 2003. Plant traits as predictors of performance in ecological restoration. Journal of Applied Ecology 40, 65-77.

Sheley, R.L., Half, M.L., 2006. Enhancing native forb establishment and persistence using a rich seed mixture. Restoration Ecology 14, 627-635.

Smith, H., Feber, R., Macdonald, D., 1999. Sown field margins: why stop at grass? Aspects of Applied Biology 54, 275-282.

Stoate, C., Boatman, N.D., Borralho, R.J., Rio Carvalho, C.R., de Snoo, G.R., Eden, P., 2001. Ecological impacts of arable intensification in Europe. Journal of Environmental Management 63, 337-365.

Stoll, P., Prati, D., 2001. Intraspecific aggregation alters competitive interactions in experimental plant communities. Ecology 82, 319-327.

Weigelt, A., Schumacher, J., Walther, T., Bartelheimer, M., Steinlein, T., Beyschlag, W., 2007. Identifying mechanisms of competition in multi-species communities. Journal of Ecology 95, 5364.

Westbury, D.B., Woodcock, B.A., Harris, S.J., Brown, V.K., Potts, S.G., 2008. The effects of seed mix and management on the abundance of desirable and pernicious unsown species in arable buffer strip communities. Weed Research 48, 113-123. 


\section{Chapter 2}

Spatial aggregation facilitates coexistence and diversity of wild plant species in field margins

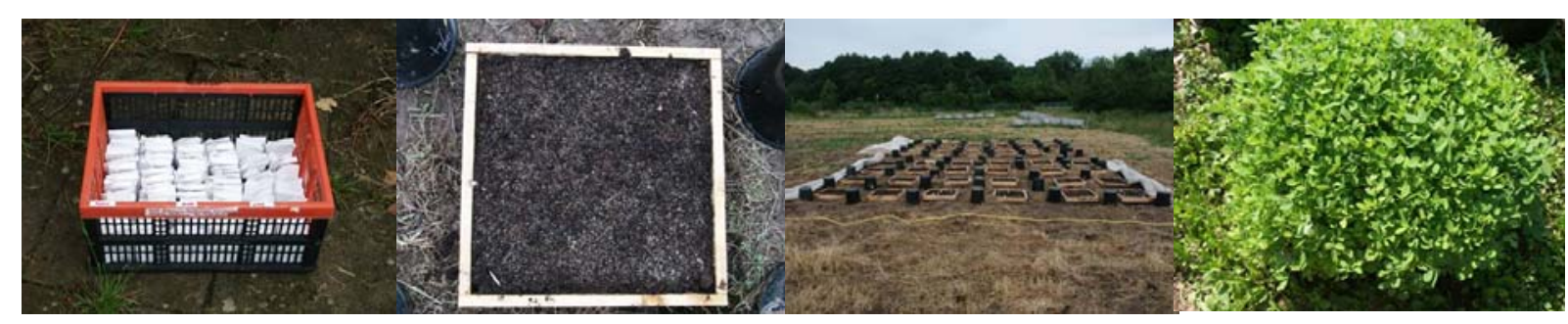

Birte Eleen Waßmuth Peter Stoll Teja Tscharntke Carsten Thies 


\begin{abstract}
European agri-environment schemes encourage farmers to establish sown field margin strips to protect and enhance wild plant diversity. However, plant diversity in such wild plant sowings based on seed-mixtures is often low due to the high competitiveness of few, common species. Here we analysed whether intraspecific aggregation could enhance the performance of less competitive species, and how plant performance is influenced by the number of species in a mixture. We focused on inter- and intraspecific competition between six agricultural wild plant species (Centaurea cyanus, Calendula arvensis, Melilotus officinalis, Poa annua, Bromus mollis, Medicago lupulina), and tested (i) two different seeding patterns (intraspecifically aggregated vs. randomly dispersed) and (ii) three different species mixtures (monocultures, three-species, and six-species mixtures). Plant performance was measured in terms of number of individuals, biomass per individual and biomass per $\mathrm{m}^{2}$. Intraspecific aggregation resulted in higher numbers of individuals of all species, while mixtures generated lower numbers of individuals. The performance of plant species differed depending on their position in the competitive hierarchy. Competitively weak species suffered much less from intraspecific than interspecific competition in terms of biomass, and the competitively weakest species became even excluded in the most species rich and randomly dispersed sowings with high interspecific competition. In conclusion, the performance of wild plant species was influenced by both seeding pattern and number of species in a mixture. Intraspecific aggregation enabled the coexistence of competitively weak species by reducing interspecific competitive exclusion processes. Consequently, agri-environmental schemes designed to preserve and enhance biodiversity should consider small-scale processes influencing the distribution and abundance of plants, and develop new agricultural sowing technologies to cultivate competitively weak and endangered wild plant species.
\end{abstract}

Keywords: annuals; biodiversity conservation; interspecific and intraspecific competition; seeding pattern. 


\section{Introduction}

Wild plant species in agricultural habitats in Europe are declining since uncultivated edges and crop field boundaries have been removed (Kleijn et al. 1998; Wilson and Aebischer 1995, Critchley and Fowbert 2000). In Germany the "Red List" of endangered plant species includes 93 agricultural wild plant species; thereof 15 plant species are already extinct. Field boundary strips are often suggested to protect and re-establish diverse plant communities especially of endangered arable weeds, which are mostly annual species (Eggenschwiler et al. 2004; Critchley et al. 2006; Walker et al. 2007). However, natural development of the vegetation is often much less diverse than expected (Kleijn et al. 1998; Asteraki et al. 2004). The main reason is that the developing plant species richness of field margin strips depends not only on the available species pool or the introduced seed mixture, but also on the dominance of competitively strong species in the local seed bank (Denys et al. 1997; Kirkham et al. 1999; Anderlik-Wesinger 2000; Denys and Tscharntke 2002; Lepš et al. 2007). Therefore, creating diverse plant mixtures has been shown to be difficult even when seed mixtures are based on careful selection (Smith et al. 1994; Bokenstrand et al. 2004; Kiehl et al. 2006). Such underlying processes in field margins are documented by these studies, suggesting that the extent of competitive displacement may increase in the first years. However, more detailed knowledge on the competitive ability of individual plant species is necessary to better understanding the dynamics of plant communities.

Unsprayed field margin strips usually support only 7-21 very common and competitively strong species in Germany (Zwerger 2002). Interspecific competition appears to exclude naturally weak competitors in field margin strips. Several studies have shown that the performance of an individual plant can be predicted by the number and identity of neighbours and their distance to them (Bergelson 1990; Hitchmough 2000; Turnbull et al. 2004; Stoll and Bergius 2005; Weigelt et al. 2007; Wallin et al. 2008), and may be stronger affected by conspecifics than by heterospecifics (Conolly et al. 1990; Amarasekare 2003; Bolker et al. 2003). In monocultures, plant individuals can experience intense intraspecific competition, while in mixed plant communities they may experience a shift from intraspecific to interspecific competition depending on community composition and resource availability (Stoll and Prati 2001; Jumpponen et al. 2005; Monzeglio and Stoll 2005). Intraspecific competition is often assumed to be more intense than interspecific competition since individuals of the same species are more likely to share the same resource demands (Aguiar et al. 2001; Warren et al. 2002; Amarasekare 2003; Gustafsson 
and Ehrlén 2003; Suter et al. 2007; Turnbull et al. 2007; but see Harpole and Suding 2007). However, this may be species-specific as the relative importance of intraspecific versus interspecific competition can change depending on plant community composition. For example, a competitively weak species may be expected to suffer less from conspecifics than from competitively strong heterospecifics (Stoll and Prati 2001).

In this study, we simulated annually sown margin strips which are eligible to incentives in Germany (BMELV 2005, 2007). We focused on the effects of intra- and interspecific competition of six annual wild plant species (Centaurea cyanus, Calendula arvensis, Melilotus officinalis, Poa annua, Bromus mollis, Medicago lupulina) with the aim to establish competitively weak plant species, and thereby, enhance plant biodiversity. We established 72 plots to test the performance of wild plant species, thereby simulating the situation in sown field margin strips, and analysed whether intraspecific aggregation enhances the performance of less competitive species, and how plant performance is influenced by the number of species in a mixture. We tested (i) two different seeding patterns (intraspecifically aggregated vs. randomly dispersed) and (ii) three different species mixtures (monocultures, three-species and six-species mixtures). We expected that the performance of competitively weak species would be enhanced when grown intraspecifically aggregated and that this effect would be more pronounced in mixtures with six species compared to mixtures with three species.

\section{Material and Methods}

Study species and Experimental design

We used six different annual species Centaurea cyanus (L.), Calendula arvensis (L.), Melilotus officinalis (L.), Poa annua (L.), Bromus mollis (L.), and Medicago lupulina (L.) following recommendations for seed mixtures to be used in margins and/or flower strips. All species are typical plants of ruderal sites and can be found in field margins (Rothmaler 1988; Davies and Carnegie 1994; Critchley 2000; Andreasen and Stryhn 2008). We set up a randomized block design with a total of 72 plots (in three blocks) and established sowings in (i) two different seeding patterns (intraspecifically aggregated (aggr) vs. randomly dispersed (ran)) and in (ii) three different species mixtures (monocultures (mono), two different three-species mixtures (3sp), and six-species mixtures (6sp)). We analysed monocultures of each of the six species, three-species mixtures of Centaurea, Poa and Medicago, three-species mixtures of Calendula, Bromus and Melilotus, and six- 
species mixtures of all species. Seeds of all species were of local provenance and were obtained from a commercial supplier (Rieger-Hofmann GmbH, Blaufelden, Germany). Seeding density was $6 \mathrm{~g} / \mathrm{plot}$ ( $1 \mathrm{~g}$ per species in a six-species mixture, $2 \mathrm{~g}$ per species in a three-species mixture, etc.), equalling $24 \mathrm{~g} / \mathrm{m}^{2}$. Thus the sowing density was determined by seed weight per area according to agricultural sowing practices (cf. Thorhallsdottir 1990). The thousand seed weights were as follows: Calendula 9.0g, Centaurea 3.8g, Bromus 2.8g, Medicago 2.2g, Melilotus 2.0g, and Poa $0.15 \mathrm{~g}$. The plots consisted of wooden frames $(0.5 \mathrm{~m} \times 0.5 \mathrm{~m}$, height: $0.08 \mathrm{~m})$ filled with common garden soil (Archut ${ }^{\circledR}$, Frühstorfer Erde Typ T25, Hawita Gruppe Oldenburg) on an unfertilized arable field. The frames were open to the loamy ground to allow rooting. Plots were separated by $0.5 \mathrm{~m}$ wide aisles. The treatments were replicated six times (three-, and six-species mixtures) and three times (monocultures), respectively, representing an unbalanced design. Intraspecifically aggregated plots were divided into six subplots $(0.16 \mathrm{~m} \times 0.25 \mathrm{~m})$ using a template. Each species occupied six subplots in monoculture, two subplots in the three-species and one subplot in the six-species mixtures. The random plots were sown with the equivalent number of seeds. Species were randomly mixed before sowing and were spread as evenly distributed as possible over the whole plot. The sowings were done in July 2005 (Julian date 181). After sowing we spread a thin layer of soil over the seeds and covered the plots with gaze for the first days to protect the seeds from heavy rainfall and strong winds. Plots were watered and weeded regularly.

\section{Data Collection and Sampling Methods}

For each species we counted the number of individuals per plot in randomly chosen one quadrate of $10 \times 10 \mathrm{~cm}$ (forbs and legumes) and four quadrates of $3 \times 3 \mathrm{~cm}$ (grasses) per plot, respectively (Mouquet et al. 2004) and extrapolated the numbers to $\mathrm{m}^{2}$. Grass stems were counted as individuals. All plants were harvested during the flowering period (Julian date 249). We cut all plants near the ground, sorted them into species, dried them for $48 \mathrm{hrs}$ at $105^{\circ} \mathrm{C}$ and weighed the aboveground biomass to the closest $0.01 \mathrm{~g}$.

\section{Competitive Ability}

We calculated competitive abilities (CA) following Stoll and Prati (2001) to define the species as competitively strong or weak. CA's were calculated by dividing the biomass in mixture by biomass in monoculture. The calculations were done for the randomly 
dispersed six-species mixtures. The two replicates per species (treatment combination and block) were averaged before dividing by the monoculture biomass of the corresponding block.

\section{Statistical Analysis}

Statistical analyses were done using the software package R 2.6.2 (R Development core Team 2008). Data were log or square root transformed where appropriate and analyzed by means of ANOVA and a post-hoc Tukey (HSD) test to distinguish interactions between treatment levels. To elucidate species responses on predictor variables, we tested the variables block (1-3), spatial seeding pattern (aggregated vs. random), and number of species in mixture (monoculture, three-species, six-species). Each species was analyzed separately. In addition, simple regressions were used to test for the relationship between $\mathrm{CA}$ and species-specific traits (biomass, mean plant height, flowering time and seed size).

\section{Results}

Intra- vs. interspecific competition

The competitive ability (CA) for Centaurea, Calendula and Melilotus was $>1$ showing that intraspecific competition was stronger than interspecific competition. In contrast, the competitive ability for Poa and Bromus was $<1$ showing that interspecific competition was stronger than intraspecific competition (Table 2.1, Fig. 2.1). We did not find any Medicago individuals at the time of harvest in the randomly dispersed six-species mixture. The very few established seedlings died in the course of the experiment; therefore the CA of Medicago was 0 . The CA of species correlated positively with their biomass production in intraspecifically aggregated plots $(R=0.947, P=0.004, n=6)$, and in random plots $(R=$ $0.919, P=0.010, n=6$ ), but negatively with the ratio of biomass in intraspecifically aggregated and randomly dispersed plots $(R=-0.850, P=0.039, n=6$; Fig. 2.2). Thus biomass seemed to be crucial for competitive interactions of neighbouring plants, whereas other plant-specific traits (Table 2.1) such as plant height $(R=0.187, P=0.723)$, flowering time $(R=0.388, P=0.447)$, and seed size $(R=0.620, P=0.189)$ were not significantly correlated with CA. 
Table 2.1 Competitive abilities (CA) and species-specific attributes of six annual wild plant species. Competitive abilities were calculated as biomass of randomly dispersed six-species mixtures divided by biomass in monocultures. Mean biomass in intraspecifically aggregated and randomly dispersed plots was averaged over monocultures, three-, and six-species mixtures. Mean plant height [cm], begin of flowering [month], and seed size $[\mathrm{g}]$ (= thousand seeds weights) were taken from literature.

\begin{tabular}{lcccccc}
\hline & C. cyanus & C. arvensis & M. officinalis & P. annua & B. mollis & M. lupulina \\
\hline CA & 2.65 & 2.43 & 1.38 & 0.93 & 0.4 & 0 \\
Biomass $_{\text {agg }}[\mathrm{g}]$ & 1168 & 1225 & 839.2 & 232.4 & 291.6 & 213.1 \\
Biomass $_{\text {ran }}[\mathrm{g}]$ & 2165 & 1242 & 1137.7 & 197.4 & 209.1 & 83.75 \\
Plant height $[\mathrm{cm}]^{1)}$ & 45 & 37.5 & 65 & 16 & 42.5 & 37.5 \\
Begin flowering $_{[\text {month] }}^{1)}$ & 6 & 6 & 6 & 1 & 5 & 5 \\
${\text { Seed size }[\mathrm{g}]^{2)}}^{2)}$ & 3.8 & 9 & 2 & 0.15 & 2.8 & 2.2 \\
\hline
\end{tabular}

1) Rothmaler 1988

2) Rieger-Hofmann GmbH 2005

\section{Intraspecific aggregation vs. random dispersal}

All six species yielded higher numbers of individuals when cultivated intraspecifically aggregated (Table 2.2, Fig. 2.3a). The competitively weakest species, Medicago, produced more biomass per individual when grown intraspecifically aggregated while all other species (except Bromus) produced more biomass per individual when cultivated randomly dispersed (Table 2.2, Fig.2.3b). The two competitively weakest species, Bromus and Medicago, produced more biomass per $\mathrm{m}^{2}$ when cultivated intraspecifically aggregated, while the competitively strong species, Centaurea, produced more biomass per $\mathrm{m}^{2}$ when cultivated randomly dispersed (Table 2.2, Fig. 2.3c).

Monocultures, three-, and six-species mixtures

All species yielded a smaller number of individuals with increasing number of species in a mixture (Table 2.2, Fig. 2.4a). Centaurea, Calendula, Melilotus and Medicago increased their biomass per individual with increasing number of species (Table 2.2, Fig. 2.4b). Calendula produced more biomass per $\mathrm{m}^{2}$ when grown in a six-species mixture, this being almost twice as high as in monoculture. In contrast, Bromus and Medicago produced less biomass per $\mathrm{m}^{2}$ with increasing number of species (Table 2.2, Fig. 2.4c). 


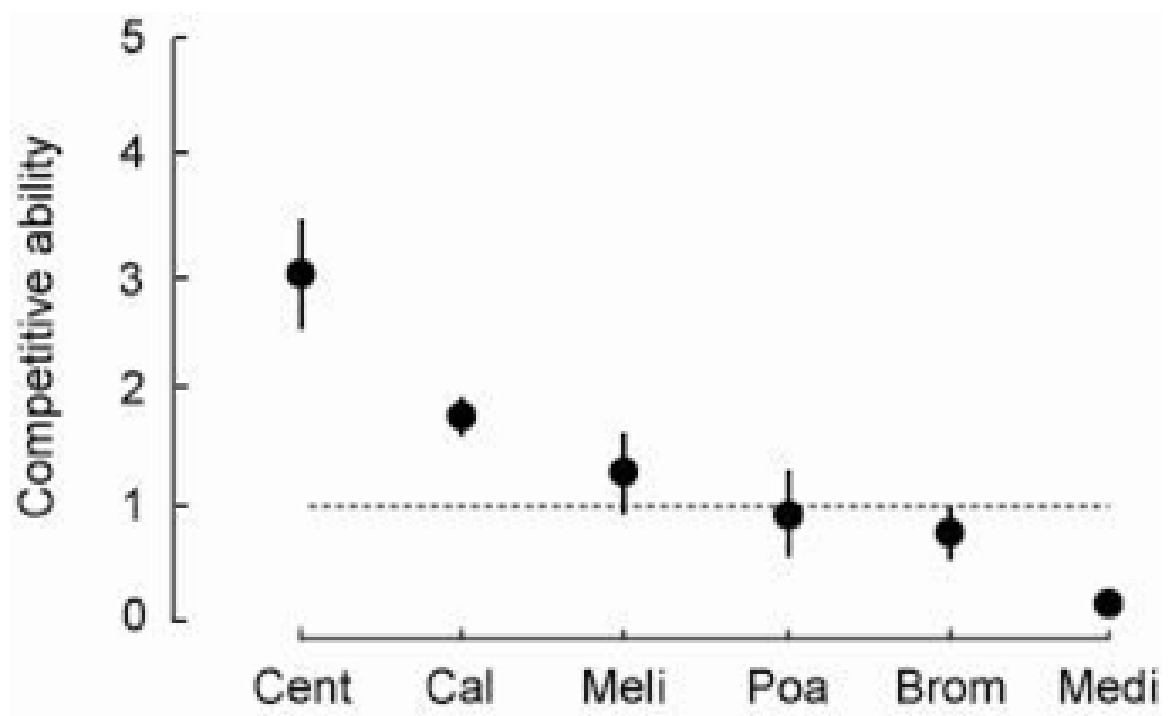

Figure 2.1 Competitive abilities (CA, mean \pm 1 standard error) of six annual wild plant species (Cent - C. cyanus, Cal - C. arvensis, Meli - M. officinalis, Poa - P. annua, Brom - B. mollis, Medi - M. lupulina). Competitive abilities were calculated from biomass in randomly dispersed sixspecies mixtures divided by biomass in monocultures.

\section{Interactions between seeding pattern and number of species in mixture}

The effect of the seeding pattern on the number of individuals per $\mathrm{m}^{2}$ differed depending on the number of species in mixture for all species (interaction: seeding pattern $\times$ no. of species in mixture; Table 2.2). The competitively weak species, Poa and Bromus, yielded more individuals in monocultures and in intraspecifically aggregated three- and six-species mixtures and the seeding pattern effect increased particularly for Bromus. The competitively strong species, Calendula and Melilotus, responded similar, i.e. the seeding pattern effect increased with increasing number of species in the mixtures. There were no individuals of the competitively weakest species, Medicago, in the randomly dispersed sixspecies mixture; therefore that mixture differed significantly from all other combinations.

The effect of the seeding pattern on the biomass per individual also differed depending on the number of species in mixture. Calendula and Melilotus grown in randomly dispersed three-, and six-species mixtures produced more biomass per individual than in monocultures (interaction: seeding pattern $\times$ no. of species in mixture; Table 2.2). 
Table 2.2 Effects of seeding pattern and number of species in seed mixtures on the number of individuals per $\mathrm{m}^{2}$, biomass per individual $[\mathrm{g}]$ and biomass per $\mathrm{m}^{2}[\mathrm{~g}]$ of six annual wild plant species. Block $(1-3$, d.f. $=2)$, seeding pattern (intraspecific aggregation vs. random dispersal, d.f. $=1$ ), no. of species (monocultures vs. three- and six-species mixtures, d.f. $=2)$, interaction $($ d.f. $=2)$ (ANOVA). Residual degrees of freedom $=22$ for all $F$-values. Data were log transformed $(C$. arvensis: individuals per $\mathrm{m}^{2}$, biomass per individual, biomass per $\mathrm{m}^{2} ; M$. officinalis: individuals per $\mathrm{m}^{2}$, biomass per individual; $P$. annua: biomass per $\mathrm{m}^{2}$; M. lupulina: individuals per $\mathrm{m}^{2}$ ) or squareroot transformed (C. cyanus: biomass per individual; $P$. annua: individuals per $\mathrm{m}^{2}$, biomass per individual; B. mollis: individuals per $\mathrm{m}^{2}$, biomass per individual) when necessary to achieve homoscedasticity and normal distributions of residuals. Monocultures were replicated three times, all other treatment combinations were replicated six times.

\begin{tabular}{|c|c|c|c|c|c|c|}
\hline & \multicolumn{2}{|c|}{ No. of individuals } & \multicolumn{2}{|c|}{$\begin{array}{l}\text { Biomass per } \\
\text { individual [g] }\end{array}$} & \multicolumn{2}{|c|}{ Biomass per $\mathrm{m}^{2}[\mathrm{~g}]$} \\
\hline & $F$ & $p$ & $F$ & $p$ & $F$ & $p$ \\
\hline \multicolumn{7}{|l|}{ C. cyanus } \\
\hline Block & 13.3 & $<0.001$ & 1.1 & 0.351 & 3.7 & 0.040 \\
\hline Pattern & 7.0 & 0.015 & 16.8 & $<0.001$ & 12.5 & 0.002 \\
\hline No. of species & 5.0 & 0.017 & 3.6 & 0.046 & 2.7 & 0.088 \\
\hline Pattern $\times$ No. of species & 6.3 & 0.007 & 3.2 & 0.060 & 3.0 & 0.072 \\
\hline \multicolumn{7}{|l|}{ C. arvensis } \\
\hline Block & 0.8 & 0.449 & 2.8 & 0.085 & 6.2 & 0.007 \\
\hline Pattern & 31.1 & $<0.001$ & 11.6 & 0.003 & 0.3 & 0.618 \\
\hline No. of species & 9.8 & $<0.001$ & 8.5 & 0.002 & 3.5 & 0.048 \\
\hline Pattern $\times$ No. of species & 10.0 & $<0.001$ & 5.2 & 0.014 & 1.3 & 0.291 \\
\hline \multicolumn{7}{|l|}{ M. officinalis } \\
\hline Block & 1.6 & 0.227 & 1.3 & 0.284 & 1.0 & 0.38 \\
\hline Pattern & 43.8 & $<0.001$ & 29.8 & $<0.001$ & 2.7 & 0.12 \\
\hline No. of species & 12.6 & $<0.001$ & 4.8 & 0.019 & 0.1 & 0.93 \\
\hline Pattern $\times$ No. of species & 4.1 & 0.031 & 3.8 & 0.039 & 0.6 & 0.58 \\
\hline \multicolumn{7}{|l|}{ P. апnиа } \\
\hline Block & $1 \cdot 8$ & 0.20 & 2.9 & 0.078 & 3.1 & 0.064 \\
\hline Pattern & 153.8 & $<0.001$ & 9.9 & 0.005 & 2.2 & 0.153 \\
\hline No. of species & 25.4 & $<0.001$ & 1.6 & 0.233 & 0.6 & 0.541 \\
\hline Pattern $\times$ No. of species & 18.5 & $<0.001$ & 2.9 & 0.079 & 0.5 & 0.598 \\
\hline \multicolumn{7}{|l|}{ B. mollis } \\
\hline Block & 4.7 & 0.020 & 0.3 & 0.77 & 2.6 & 0.096 \\
\hline Pattern & 46.2 & $<0.001$ & 2.9 & 0.10 & 7.5 & 0.012 \\
\hline No. of species & 12.1 & $<0.001$ & 0.1 & 0.89 & 4.9 & 0.017 \\
\hline Pattern $\times$ No. of species & 6.0 & 0.008 & 0.2 & 0.85 & 1.4 & 0.257 \\
\hline \multicolumn{7}{|l|}{ M. lupulina } \\
\hline Block & 1.3 & 0.31 & 1.6 & 0.23 & 3.9 & 0.035 \\
\hline Pattern & 44.2 & $<0.001$ & 22.9 & $<0.001$ & 26.2 & $<0.001$ \\
\hline No. of species & 28.1 & $<0.001$ & 15.9 & $<0.001$ & 58.5 & $<0.001$ \\
\hline Pattern $\times$ No. of species & 14.7 & $<0.001$ & 2.0 & 0.16 & 0.1 & 0.891 \\
\hline
\end{tabular}




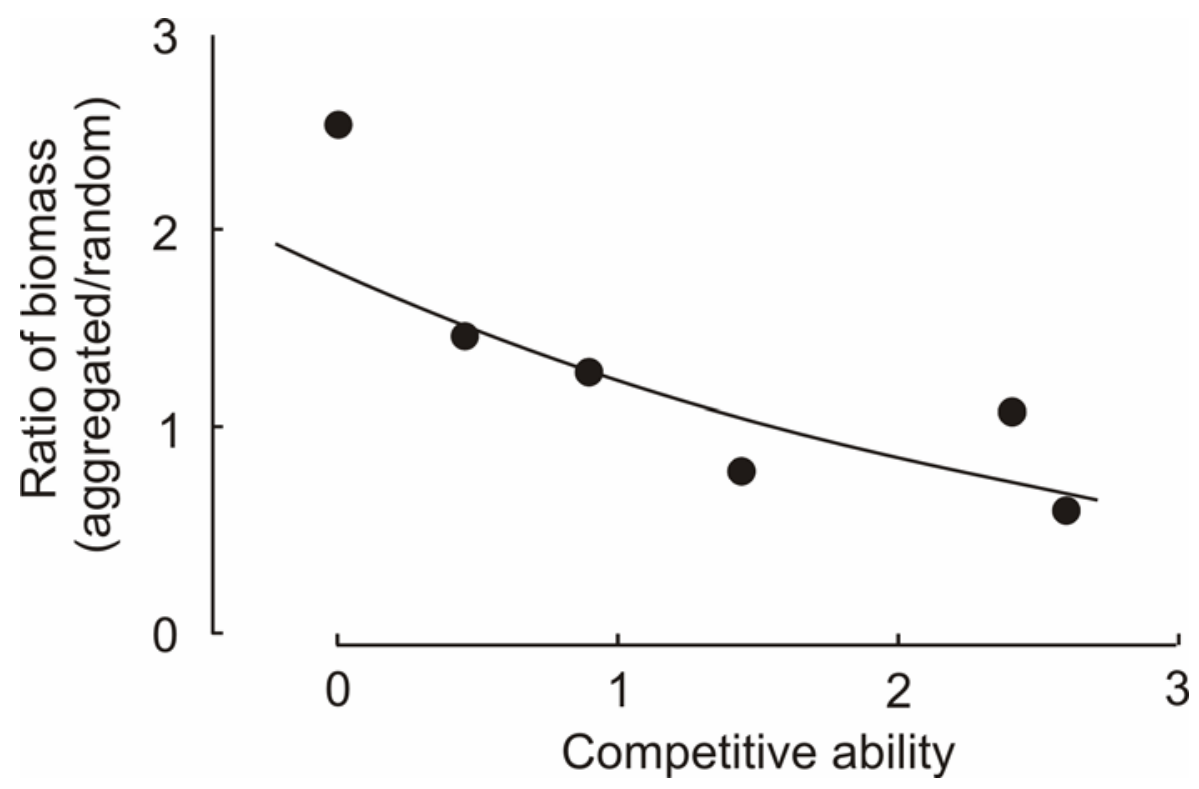

Figure 2.2 Illustrative figure showing that the competitive ability is negatively related with the ratio of the biomass in intraspecifically aggregated plots and randomly dispersed plots. The six points represent the six annual wild plant species ranked in the order of their competitive ability (see Table 2.1). 


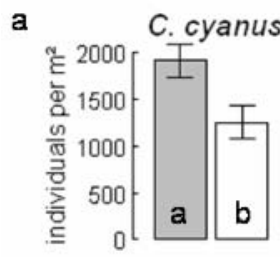

aggr ran
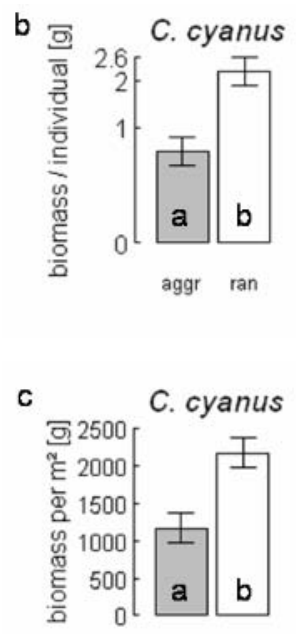

aggr ran

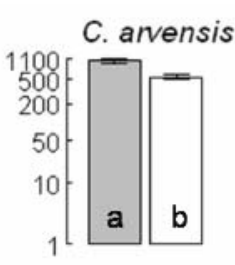

aggr ran
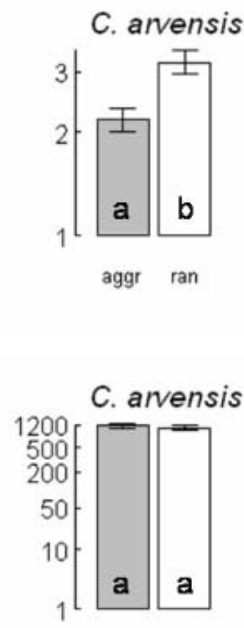

aggr ran

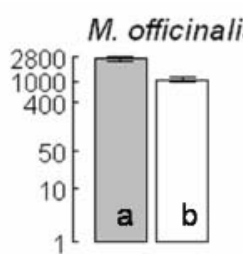

aggr ran
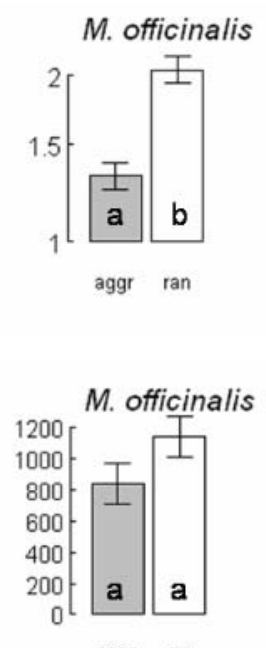

aggr ran

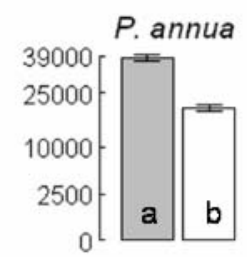

aggr ran
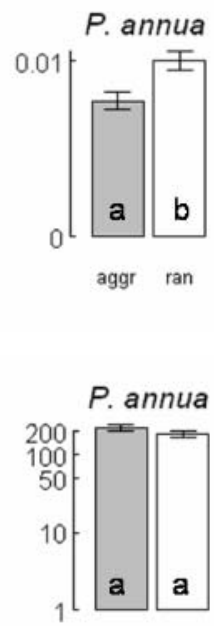

aggr ran

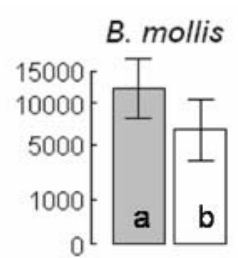

aggr ran
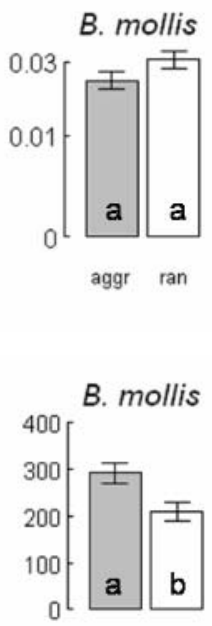

aggr ran

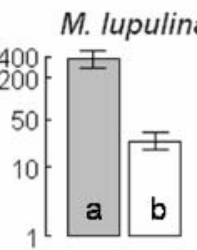

aggr ran
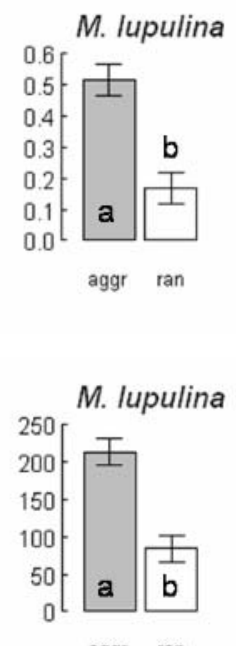

aggr ran

\section{Competitive ability}

Figure 2.3 Performance of six annual wild plant species cultivated intraspecifically aggregated (grey bars) and randomly dispersed (white bars); a) number of individuals per $\mathrm{m}^{2}, \mathrm{~b}$ ) biomass per individual $[\mathrm{g}]$ and c) biomass per $\mathrm{m}^{2}$ [g]. Mean \pm 1 standard error (average of monocultures, three-, and six-species mixtures), data were log-transformed (C. arvensis: individuals per $\mathrm{m}^{2}$, biomass per individual and biomass per $\mathrm{m}^{2} ; M$. officinalis: individuals per $\mathrm{m}^{2}$ and biomass per individual; P. annua: biomass per $\mathrm{m}^{2}$; M. lupulina: individuals per $\mathrm{m}^{2}$ ) or square root transformed (C. cyanus: biomass per individual; $P$. annua: individuals per $\mathrm{m}^{2}$ and biomass per individual; B. mollis: individuals per $\mathrm{m}^{2}$ and biomass per individual) prior to analysis (ANOVA). Different letters indicate significant differences $(P<0.05)$. Note that the y-axes differ among panels. 

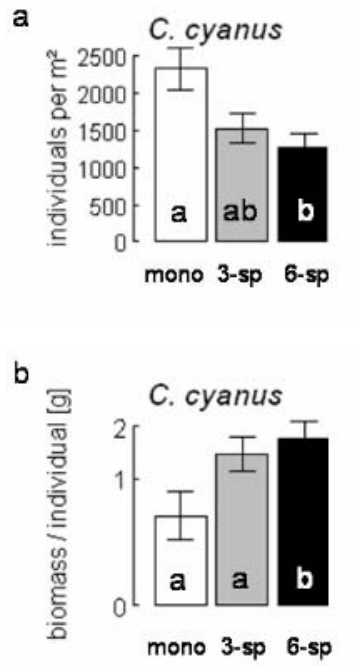

c

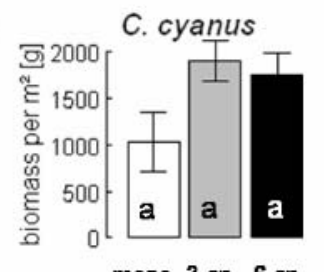

C. arvensis

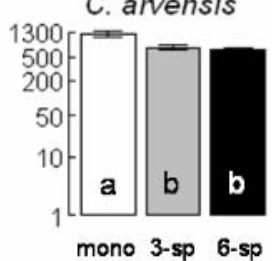

C. arvensis

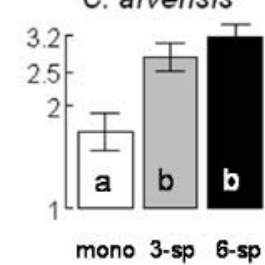

C. arvensis

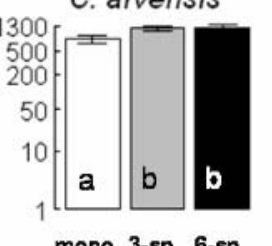

M. officinalis

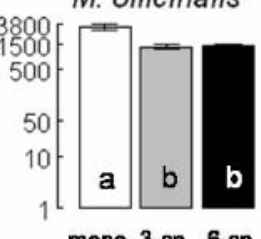

M. officinalis

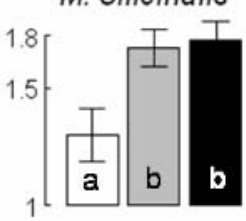

mono 3-sp 6-sp

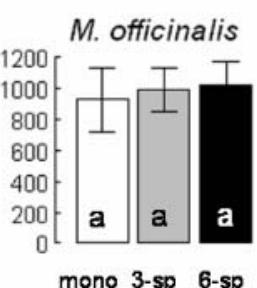

$P$. annua

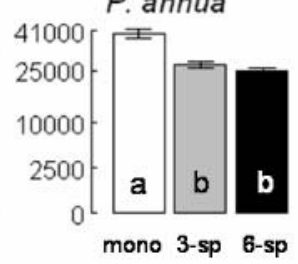

P. annua

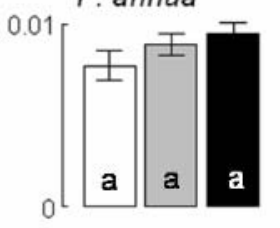

mono 3-sp 6-sp

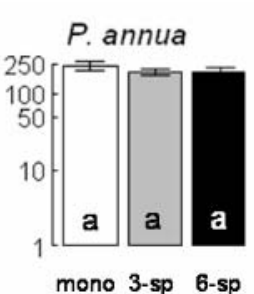

B. mollis

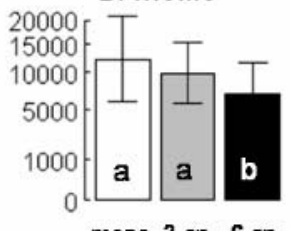

mono 3-sp 6-sp

B. mollis

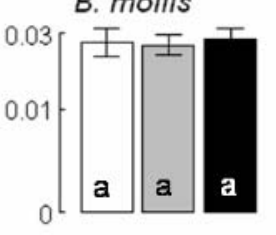

mono 3-sp 6-sp

B. mollis

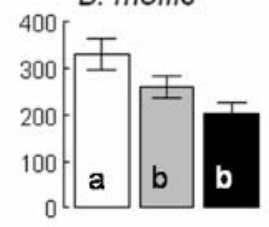

mono 3-sp 6-sp
M. Iupulina

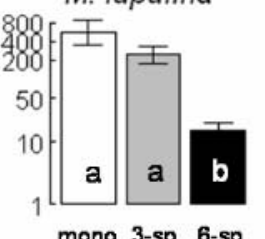

M. Iupulina

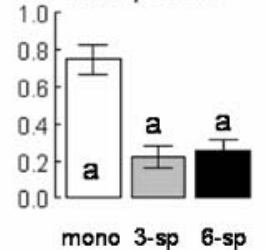

mono 3-sp 6-sp

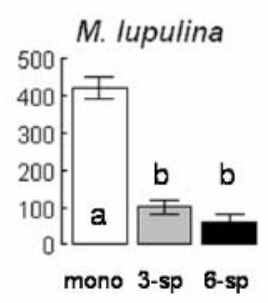

Competitive ability

Figure 2.4 Performance of six annual wild plant species cultivated in monoculture, three-, and six-species mixtures; a) number of individuals per $\mathrm{m}^{2}$, b) biomass per individual [g] and c) biomass per $\mathrm{m}^{2}$ [g]. Mean \pm 1 standard error (average of intraspecifically aggregated and random seeding patterns), data were log-transformed (C. arvensis: individuals per $\mathrm{m}^{2}$, biomass per individual and biomass per $\mathrm{m}^{2}$; $M$. officinalis: individuals per $\mathrm{m}^{2}$ and biomass per individual; $P$. annua: biomass per $\mathrm{m}^{2}$; M. lupulina: individuals per $\mathrm{m}^{2}$ ) or square root transformed (C. cyanus: biomass per individual; $P$. annua: individuals per $\mathrm{m}^{2}$ and biomass per individual; B. mollis: individuals per $\mathrm{m}^{2}$ and biomass per individual) prior to analysis (ANOVA). Monocultures were replicated three times, all other treatment combinations were replicated six times. Different letters indicate significant differences $(P<0.05$, TukeyHSD). Note that the y-axes differ among panels. 


\section{Discussion}

Comparison of intraspecifically aggregated vs. randomly dispersed seeding patterns and monocultures, three-species, and six-species mixtures showed that intraspecific aggregation resulted in higher numbers of individuals of all species. The advantage of intraspecific aggregation in terms of biomass was related to species' rank in the competitive hierarchy of the plant community. Competitively strong species appeared to suffer stronger from intraspecific than interspecific competition as their biomass per individual and/or biomass per $\mathrm{m}^{2}$ was lower when grown intraspecifically aggregated or when grown in monocultures.

In our experiment, intraspecific aggregation facilitated higher number of individuals of all species. However, only the competitively weak species, Bromus and Medicago, increased in biomass per $\mathrm{m}^{2}$, while the competitively strong species, Centaurea, decreased. Hence, intraspecific competition affected the competitively strongest species negatively, but competitively weak species positively. Such shifts from interspecific towards intraspecific competition enable coexistence (Amarasekare 2003), and are related to species-specific traits (Weigelt et al. 2002) determining the competitive hierarchy in a plant community (Monzeglio and Stoll 2005).

In our experiment, doubling species numbers from three to six did not consistently change species performance. The competitively strong species, Calendula, increased by $\sim 50 \%$ in biomass per $\mathrm{m}^{2}$ from monoculture to three-species mixture and by $\sim 75 \%$ from monoculture to six-species mixture, while the biomass per $\mathrm{m}^{2}$ of the competitively weak species, Bromus and Medicago, decreased. However, biomass per $\mathrm{m}^{2}$ of strong species increased and biomass per $\mathrm{m}^{2}$ of weak species decreased subproportionally with increasing number of species in a mixture. Similarly, the number of individuals of all species decreased subproportionally with increasing number of species in a mixture. For Medicago, the number of individuals decreased stronger from three-species to six-species mixtures than from monocultures to three-species mixtures, indicating higher intensity of competition in species rich mixtures. Therefore, our results indicate the difficulty to exactly identify intensity of competitive interactions in species mixtures due to a lack of detailed knowledge of species-specific effects of the neighbouring plants. Nevertheless, our results support the idea that the performance of competitively weak species would be particularly enhanced by intraspecific aggregation in species mixtures and that a competitively weak species might not have access to patches that are occupied by competitively strong species 
as it was the case for Medicago. Competition with two other species decreased the number of Medicago individuals, and competition with five other species caused total exclusion in plots with randomly dispersed seeding patterns.

The forbs, Centaurea and Calendula $(\mathrm{CA}>1)$ were the strongest competitors, hence suffering most from intraspecific competition, while the grasses Poa and Bromus $(\mathrm{CA}<1)$ turned out to be weak competitors, therefore suffering stronger from interspecific compared to intraspecific competition. This is in line with Harpole and Suding (2007) who found a similar difference in inter- and intraspecific competition between grasses and forbs (but see Špaéková and Lepš 2001). Only few empirical studies have analysed mechanisms of intra- and interspecific competition in plant communities (Murrel et al. 2001; Stoll and Prati 2001; Rejmánek 2002; Monzeglio and Stoll 2005; Turnbull et al. 2007; Harpole and Suding 2007), showing that local competitive neighbourhood can be an important determinant of plant performance and intraspecific aggregation to enhance coexistence (Goreaud et al. 2002; Turnbull et al. 2004), and to reduce the likelihood of competitive exclusion (Chesson and Neuhauser 2002).

In our experiment, seeding density was rather high due to the specific thousand seed weights. Seeding density is known to have distinct effects on competition between plant species (Park et al. 2003; Polley et al. 2003; De Boeck et al. 2006), and competition appears to increase with higher densities (Weiner et al. 2001). Our results showed that even at these rather high seeding densities (with intense intraspecific competition) competitively weak species may benefit from intraspecific aggregation.

In conclusion, the performance of annual wild plant species was affected by seeding pattern and number of species in a mixture. Intraspecific aggregation enabled competitively weak species to coexist. Hence, agri-environment schemes designed to preserve and enhance biodiversity should consider spatial seeding strategies enhancing survival of little competitive and endangered plant species. New agricultural sowing technologies allowing intraspecific aggregation may be an important tool for the diversification of field boundary strips, fallows and further elements of agricultural landscapes. 


\section{Acknowledgements}

We thank Diethart Matthies, Hans de Kroon and two anonymous reviewers for helpful comments on the manuscript, and Inken, Christa, and Hans Erich Waßmuth for their assistance in the field. 


\section{References}

Aguiar, M.R., Lauenroth, W.K., Peters, D.P., 2001. Intensity of intra- and interspecific competition in coexisting shortgrass species. Journal of Ecology 89, 40-47.

Amarasekare, P., 2003. Competitive coexistence in spatially structured environments: a synthesis. Ecology Letters 6, 1109-1122.

Anderlik-Wesinger, G., 2000. Spontane und gelenkte Vegetationsentwicklung auf Rainen Untersuchungen zur Effizienz verschiedener Methoden der Neuanlage. Agrarökologie 43, 283-290.

Andreasen, C., Stryhn, H., 2008. Increasing weed flora in Danish arable fields and its importance for biodiversity. Weed Research 48, 1-9.

Asteraki, E.J., Hart, B.J., Ings, T.C., Manley, W.J., 2004. Factors influencing the plant and invertebrate diversity in arable field margins. Agriculture, Ecosystems and Environment 102, 219231.

Bergelson, J., 1990. Life after Death: Site pre-emption by remains of P. annua. Ecology 71, 21572165.

Bokenstrand, A., Lagerlöf, J., Torstensson, P.R., 2004. Establishment of vegetation in broadened field boundaries in agricultural landscapes. Agriculture, Ecosystems and Environment 101, 21-29.

BMELV, 2005. Nationale Rahmenregelung der Bundesrepublik Deutschland für die Entwicklung ländlicher Räume. Berlin.

BMELV, 2007. Grundsätze für die Förderung einer markt- und standortangepassten Landbewirtschaftung. Berlin.

Bolker, B.M., Pacala, S.W., Neuhauser, C., 2003. Spatial dynamics in model plant communities: what do we really know? The American Naturalist 162, 135-148.

Chesson, P., Neuhauser, C., 2002. Intraspecific aggregation and species coexistence. Trends in Ecology and Evolution 17, 210.

Conolly, J., Wayne, P., Murray, R., 1990. Time course of plant-plant interactions in experimental mixtures of annuals: density, frequency, and nutrient effects. Oecologia 82, 513-526.

Critchley, C.N.R., Fowbert, J.A., 2000. Development of vegetation on set-aside land for up to nine years from a national perspective. Agriculture, Ecosystems and Environment 79, 159-174.

Critchley, C.N.R., Fowbert, J.A., Sherwood, A.J., 2006. The effects of annual cultivation on plant community composition of uncropped arable field boundary strips. Agriculture, Ecosystems and Environment 113, 196-205.

Critchley, C.N.R., 2000. Ecological assessment of plant communities by reference to species traits and habitat preferences. Biodiversity and Conservation 9, 87-105.

Davies, D.H.K., Carnegie, H.M., 1994. Vegetation patterns and changes in field boundaries and conservation headlands in scottish arable fields. BCPC Monograph 58, 173-184. 
De Boeck, H.J., Nijs, I., Lemmens, C.M.H.M., Ceulemans, R., 2006. Underlying effects of spatial aggregation (clumping) in relationships between plant diversity and resource uptake. Oikos 113, 269-278.

Denys, C., Thies, C., Fischer, R., Tscharntke, T., 1997. Die ökologische Bewertung von Ackerrandstreifen im integrierten Landbau. Mitteilungen der NNA 3, 2-11.

Denys, C., Tscharntke, T., 2002. Plant-insect communities and predator-prey ratios in field margin strips, adjacent crop fields, and fallows. Oecologia 130, 315-324.

Eggenschwiler, L., Jacot, K.A., Edwards, P.J., 2004. Bedeutung von Samenmischungen und Schnitt für Bunt- und Rotationsbrachen. Natur und Landschaft 79, 544-550.

Goreaud, F., Loreau, M., Millier, C., 2002. Spatial structure and survival of an inferior competitor: a theoretical model of neighbourhood competition in plants. Ecological Modelling 158, 1-19.

Gustafsson, C., Ehrlén, J., 2003. Effects of intraspecific and interspecific density on the demography of a perennial herb, Sanicula europaea. Oikos 100, 317-324.

Harpole, W.S., Suding, K.N., 2007. Frequency-dependence stabilizes competitive interactions among four annual plants. Ecology Letters 10, 1-6.

Hitchmough, J.D., 2000. Establishment of cultivated herbaceous perennials in purpose-sown native wildflower meadows in south-west Scotland. Landscape and Urban Planning 51, 37-51.

Jumpponen, A., Mulder, C.P.H., Huss-Danell, K., Högberg, P., 2005. Winners and losers in herbaceous plant communities: insights from foliar carbon isotope composition in monocultures and mixtures. Journal of Ecology 93, 1136-1147.

Kiehl, K., Thormann, A., Fadenhauer, J., 2006. Evaluation of initial restoration measures during the restoration of calcareous grasslands on former arable fields. Restoration Ecology 14, 148-156.

Kirkham, F.W., Sherwood, A.J., Oakley, J.N., Fielder, A.G., 1999. Botanical composition and invertebrate populations in sown grass and wildflower margins. Aspects of Applied Biology 54, 291-298.

Kleijn, D., Joenje, W., Le Coeur, D., Marshall, E.J.P., 1998. Similarities in vegetation development of newly established herbaceous strips along contrasting European field boundaries. Agriculture, Ecosystems and Environment 68, 13-26.

Lepš, J., Doležal, J., Bezemer, T.M., Brown, V.K., Hedlund, K., Igual Arroyo, M., Jörgensen, H.B., Lawson, C.S., Mortimer, S.R., Peix Geldart, A., Rodiguez Barrueco, C., Santa Regina, I., Šmilauer, P., van der Putten, W.H., 2007. Long-term effectiveness of sowing high and low diversity seed mixtures to enhance plant community development on ex-arable fields. Applied Vegetation Science $10,97-110$.

Monzeglio, U., Stoll, P., 2005. Spatial patterns and species performances in experimental plant communities. Oecologia 145, 619-628.

Mouquet, N., Leadley, P.M., Loreau, M., 2004. Immigration and local competition in herbaceous plant communities: a three-year seed-sowing experiment. Oikos 104, 77-90. 
Murrel, D.J., Purves, D.W., Law, R., 2001. Uniting pattern and process in plant ecology. Trends in Ecology and Evolution 16, 529-530.

Park, S.E., Benjamin, L.R., Watkinson, A.R., 2003. The theory and application of plant competition models: an agronomic perspective. Annals of Botany 92, 741-748.

Polley, W.H., Wilsey, B.J., Derner, J.D., 2003. Do species evenness and plant density influence the magnitude of selection and complementarity effects in annual plant species mixtures? Ecology Letters 6, 248-256.

Rejmánek, M., 2002. Intraspecific aggregation and coexistence. Trends in Ecology and Evolution 17, 209-210.

Rieger-Hofmann GmbH, 2005. Samen und Pflanzen gebietsheimischer Wildblumen und Wildgräser aus gesicherten Herkünften. Blaufelden.

Rothmaler, W., 1988. In: Schubert, R., Jäger, E., Werner, K. (Eds.), Exkursionsflora für die Gebiete der DDR und BRD, Atlas der Gefäßpflanzen. Volk und Wissen, Berlin.

Smith, H., Feber, R.E., MacDonald, D.W., 1994. The role of wildflower seed mixtures in field margin restoration. BCPC Monograph 58, 289-294.

Špaéková, H., Lepš, J., 2001. Procedure for separating the selection effect from other effects in diversity-productivity relationship. Ecology Letters 4, 585-594.

Stoll, P., Prati, D., 2001. Intraspecific aggregation alters competitive interactions in experimental plant communities. Ecology 82, 319-327.

Stoll, P., Bergius, E., 2005. Pattern and process: competition causes regular spacing of individuals within plant populations. Journal of Ecology 93, 395-403.

Suter, M., Ramseier, D., Guesewell, S., Connolly, J., 2007. Convergence patterns and multiple species interactions in a designed plant mixture of five species. Oecologia 151, 499-511.

Thórhallsdóttir, T.E., 1990. The dynamics of five grasses and white clover in a simulated mosaic sward. The Journal of Ecology 78, 909-923.

Turnbull, L.A., Coomes, D., Hector, A., Rees, M., 2004. Seed mass and the competition/ colonization trade-off: competitive interactions and spatial patterns in a guild of annual plants. Journal of Ecology 92, 97-109.

Turnbull, L.A., Coomes, D.A., Purves, D.W., Rees, M., 2007. How spatial structure alters population and community dynamics in a natural plant community. Journal of Ecology 95, 79-89.

Walker, K.J., Crichtley, C.N.R., Sherwood, A.J., Large, R., Nuttall, P., Hulmes, S., Rose, R., Mountford, J.O., 2007. The conservation of arable plants on cereal field margins: An assessment of new agri-environment scheme options in England, UK. Biological Conservation 136, 260-270.

Wallin, L., Svensson, B.M., Lönn, M., 2008. Artificial dispersal as a restoration tool in meadows: sowing or planting? Restoration Ecology, doi: 10.1111/j.1526-100X.2007.00350.x 
Warren, J., Wilson, F., Diaz, A., 2002. Competitive relationships in a fertile grassland community does size matter? Oecologia 132, 125-130.

Weigelt, A., Steinlein, T., Beyschlag, W., 2002. Does plant competition intensity rather depend on biomass or on species identity? Basic and Applied Ecology 3, 85-94.

Weigelt, A., Schumacher, J., Walther, T., Bartelheimer, M., Steinlein, T., Beyschlag, W., 2007. Identifying mechanisms of competition in multi-species communities. Journal of Ecology 95, 5364.

Weiner, J., Stoll, P., Muller-Landau, H., Jasentuliyana, A., 2001. The effects of density, spatial pattern, and competitive symmetry on size variation in simulated plant populations. The American Naturalist 158, 438-450.

Wilson, P.J., Aebischer, N.J., 1995. The distribution of dicotyledonous arable weeds in relation to distance from the field edge. Journal of Applied Ecology 32, 295-310.

Zwerger, P., 2002. Bericht aus dem Institut für Unkrautforschung, Braunschweig. Jahresbericht der Biologischen Bundesanstalt für Land- und Forstwirtschaft, 79-84. 


\section{Chapter 3}

Increasing the scale of intraspecific aggregation facilitates competitively weak plants

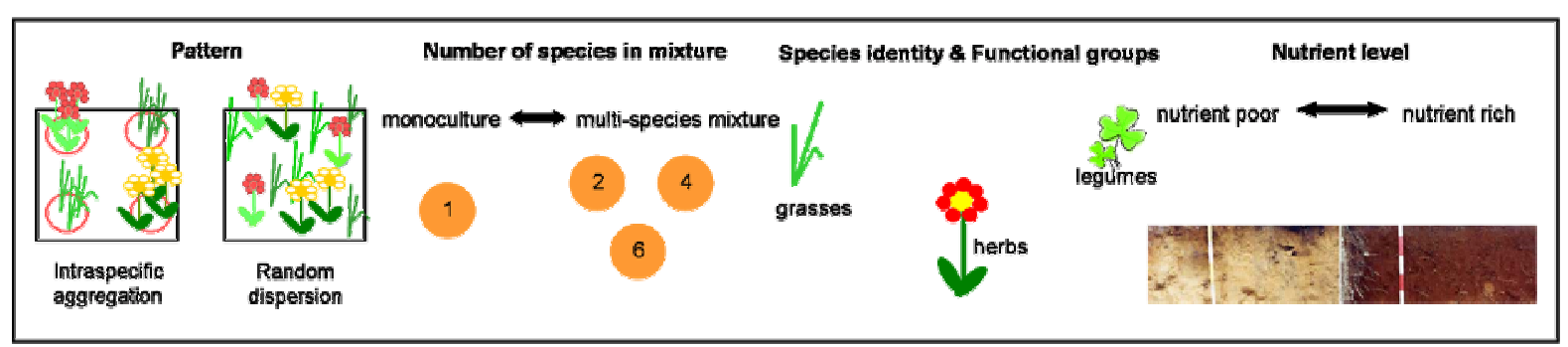

Birte Eleen Waßmuth

Teja Tscharntke

Peter Stoll

Carsten Thies 


\section{Abstract}

1. Diversity of agricultural wild plant species is declining and successful management actions are widely missing. Although current agri-environmental schemes encourage farmers to establish sown field margin strips, their success is often limited. Even if species rich mixtures are sown, this usually results in species-poor plant communities, dominated by few very competitive species.

2. In this study, we tested the hypotheses that (i) intraspecific aggregation enhances performance of competitively weak species, (ii) particularly when fertilization enhances competition, and that (iii) functional groups respond differently to competition depending on species composition.

3. The competitively weak species benefited from the decreasing interspecific competition with increasing scale of intraspecific aggregation and yielded more biomass. Fertilization also enhanced the performance, however for the legumes this was only the case in intraspecifically aggregated plots. Functional group composition mattered in that legumes increased grass biomass, while legumes performed better with grasses than with forbs.

4. Synthesis and Applications: We showed that intraspecific aggregation can enhance coexistence in seeding mixtures with improved results for weak competitors when the spatial scale of aggregation is increased. In case of intraspecific aggregation even fertilization does not inhibit competitively weak species; hence, intraspecific aggregation can enhance performance even in nutrient rich plots. Functional group composition is also important with legume species enhancing the overall performance of the mixture. In summary, intraspecifically aggregated instead of the traditional random seeding of field margin strips and fallows is a simple measure to enhance und sustain biodiversity in agricultural landscapes.

Keywords: Bromus mollis; Calendula arvensis; Centaurea cyanus; coexistence; intra- and interspecific competition; Medicago lupulina; nutrients; Poa annua; spatial scale; Trifolium campestre. 


\section{Introduction}

Biodiversity in agricultural habitats has been declining and adequate management (and its evaluation) to protect those species is widely missing (Kleijn and Sutherland 2003). Conservation schemes to enhance wild plant species in agricultural landscapes include the establishment of sown field margin strips (Stoate et al. 2001; Oppermann 2003; De Cauwer et al. 2008; Westbury et al. 2008). Although some studies found a positive correlation of number of sown plant species and established plant species (Eggenschwiler et al. 2004; Lawson et al. 2004), sowing species rich seed mixtures often results in plant communities with a few, common and very competitive species (Critchley and Fowbert 2000; Lepš et al. 2001; Pakeman et al. 2002).

There are a variety of indices to describe competition and competitive ability (for an overview see Weigelt and Jolliffe 2003), while the mechanisms of plant competition and coexistence are still poorly understood. Competition can be divided into intra- and interspecific competition and the species-specific response to competition may depend on the distance, number, identity, and diversity of neighbouring plants (Stoll and Weiner 2000; Turnbull et al. 2004). Intraspecific competition is widely assumed to be stronger than interspecific competition (Freckleton and Watkinson 2000; Suter et al. 2007; but see Naeem et al. 2000; Aguiar et al. 2001), thereby enhancing coexistence of plant species (Amarasekare 2003). However, competitively inferior plant species appear to suffer stronger from interspecific than from intraspecific competition and produce more biomass when grown among conspecifics (Stoll and Prati 2001; Monzeglio and Stoll 2005; Mokany et al. 2008). On the other hand, competitively superior species are suppressed by strong intraspecific competition (Stoll and Prati 2001; Monzeglio and Stoll 2005; De Boeck et al. 2006; Turnbull et al. 2007). Positive effects of intraspecific aggregation have been shown for forbs and grasses (Stoll and Prati 2001; Monzeglio and Stoll 2005; Harpole and Suding 2007; Mokany et al. 2008) as well as for trees (Goreaud et al. 2002; but see Stoll and Newbery 2005). However, effects of different scales of intraspecific aggregations and possible interactions with fertilization are still little known (Gunton and Kunin 2007).

Competition by competitively strong species is known to be more severe in nutrient rich habitats where competitively weak species are suppressed and excluded (Lepš 1999; Lawson et al. 2004). Hence, competition in field margin strips can be high although they are not fertilized but might still be relatively nutrient rich depending on site-specific soil characteristics and the intensity of the former cultivation. 
The functional group (e.g. herbaceous, grass or legume species) of the component species might be more important for the success of sown seed mixtures than the bare number of species in the mixture. According to Spehn et al. (2002), total plant biomass increases with diversity, but most of the diversity effects are attributable to the presence of $\mathrm{N}$-fixing species. Forbs are often not included in seed mixtures because they are difficult to establish (Sheley and Half 2006; Weigelt et al. 2007), whereas grasses often quickly build up large populations (Lawson et al. 2004; Weigelt et al. 2007). Seed mixtures with a high percentage of grasses result in less diverse plant communities than seed mixtures with few or no grasses (Eggenschwiler et al. 2004; Sheley and Half 2006). Therefore, an assemblage with forbs and legumes rather than (only) grasses has been suggested for conservation areas.

In our experiment, we simulated annually sown field margin strips and studied whether the performance (i.e. biomass production) of competitively weak species and their coexistence with competitively superior species could be enhanced by intraspecifically aggregated seeding patterns, functional group composition, and nutrient management. We hypothesized that (i) intraspecific aggregation enhances the performance of competitively weak species because they experience a shift from strong interspecific competition towards weaker intraspecific competition, and (ii) that the positive effect of intraspecific aggregation is more pronounced with increasing spatial scale of intraspecific aggregation. Furthermore, we expected (iii) a greater importance of intraspecific aggregation in nutrient rich soils for competitively weak species, but including an even better performance of competitively weak species when intraspecifically aggregated, and (iv) a positive effect of legumes on the performance of non-legume neighbours in the mixtures.

\section{Materials and Methods}

\section{Plant species}

We studied six annual wild plant species of three functional groups: the grasses (G) Poa annua (L.) and Bromus mollis (L.), the forbs (F) Calendula arvensis (L.) and Centaurea cyanus (L.), and the legumes (L) Trifolium campestre (L.) and Medicago lupulina (L.). All species are components of recommended seed mixtures for margin strips in agricultural landscapes and/or are boundary species of arable fields in Central Europe (Davies and Carnegie 1994; Critchley 2000; Storkey and Westbury 2007). We classified all species into competitively strong and competitively weak according to the results of a 
previous study (Waßmuth et al. unpublished data) where we calculated the competitive ability of each plant species following Stoll and Prati (2001). The competitive ability was calculated by dividing the biomass in mixture by the biomass in monoculture. According to the competitive abilities, Calendula and Centaurea were classified as competitively strong species, while Poa, Bromus, and Medicago were classified as competitively weak. Trifolium was not included in the first experiment, however, we expected Trifolium to be a weak competitor since it is a similar legume species.

\section{Experimental design}

On an experimental field in Göttingen (Germany) a randomized block design was set up containing four blocks and a total of 168 plots. Plots were $0.5 \times 0.5 \times 0.08 \mathrm{~m}$ and consisted of wooden frames which were filled with garden soil and were open to the ground allowing rooting and drainage. We established three different seeding patterns, random dispersal and small or large scale intraspecific aggregations. More precisely, seeding patterns were (i) random dispersal (Fig. 3.1a), (ii) small scale intraspecific aggregation with 36 subplots $(8.3 \times 8.3 \mathrm{~cm}$; Fig. $3.1 \mathrm{~b})$, and (iii) large scale intraspecific aggregation with four or six subplots $(25 \times 16.6 \mathrm{~cm}$ or $25 \times 25 \mathrm{~cm}$; Fig. 3.1c-d) depending on the number of species in a mixture. Seeding density was 100 seeds per $8.3 \times 8.3 \mathrm{~cm}$ subplot (14 $400 \mathrm{seeds} / \mathrm{m}^{2}$ ). Seeds were obtained from a commercial supplier (RiegerHofmann GmbH, Blaufelden, Germany). Species were sown in seven mixtures differing in the combination of grasses, forbs, and legumes (Table 3.1). Mixtures were 1) grasses $(G), 2)$ forbs (F), 3) legumes (L), 4) grass-forb (GF), 5) grass-legume (GL), 6) forblegume (FL), and 7) grass-forb-legume (ALL) mixtures. Depending on the mixture, each species occupied 18 (mixtures G, F, and L), nine (mixtures GF, GL, and FL), or six subplots (mixture ALL) in small scale aggregations and three, two, and one subplot in large scale aggregations, respectively (Table 3.1). We tested two nutrient levels. Nutrient poor plots contained Fruhstorfer Erde Typ Nullerde ( $\mathrm{N} 0 \mathrm{mg} / \mathrm{l}, \mathrm{P}_{2} \mathrm{O}_{5} 0 \mathrm{mg} / \mathrm{l}, \mathrm{K}_{2} \mathrm{O} 0 \mathrm{mg} / \mathrm{l}$ ), and nutrient rich plots were filled with Fruhstorfer Erde Typ T25 (N 176-264 mg/l, $\mathrm{P}_{2} \mathrm{O}_{5}$ $189-283 \mathrm{mg} / \mathrm{l}, \mathrm{K}_{2} \mathrm{O} 270-404 \mathrm{mg} / \mathrm{l}$ ) (specification of the soil attributes by $\operatorname{Archut}{ }^{\circledR}$ Fruhstorfer Erde, Hawita Gruppe Oldenburg, Germany). 
Table 3.1 Species composition in mixtures, number of species and number of subplots per species in intraspecifically aggregated plots. Study species were Poa annua (G), Bromus mollis (G), Calendula arvensis (F), Centaurea cyanus (F), Trifolium campestre (L), and Medicago lupulina (L).

\begin{tabular}{lccc}
\hline Species composition in mixtures & $\begin{array}{c}\text { Number of subplots per species } \\
\text { species }\end{array}$ & $\begin{array}{c}\text { Small scale } \\
\text { aggregation }\end{array}$ & $\begin{array}{c}\text { Large scale } \\
\text { aggregation }\end{array}$ \\
\hline Grass (G) & 2 & 18 & 3 \\
Forb (F) & 2 & 18 & 3 \\
Legume (L) & 2 & 18 & 3 \\
Grass - Forb (GF) & 4 & 9 & 2 \\
Grass - Legume (GL) & 4 & 9 & 2 \\
Forb - Legume (FL) & 4 & 9 & 2 \\
Grass - Forb - Legume (ALL) & 6 & 6 & 1 \\
\hline
\end{tabular}

The experiment started in the second week of May 2006 and continued for ten weeks until all species were flowering. After sowing, we sieved a thin layer of soil over the seeds and covered the plots with gaze for the first days to prevent the seeding pattern from strong winds. Plots were weeded and watered regularly. We tested the effects of different (i) seeding patterns, (ii) combinations of grasses, forbs, and legumes (species composition), and (iii) nutrient levels on plant performance. We evaluated the above-ground biomass production per $\mathrm{m}^{2}$ (hereafter biomass). In the last week of July 2006, plants were cut at surface level and sorted to species. Biomass was dried for $48 \mathrm{hrs}$ at $105^{\circ} \mathrm{C}$ and weighed.

\section{Statistics}

We conducted all analyses using the software package R 2.6.2 (http://www.r-project.org). Data were analysed separately for each species and were log transformed. Analyses of variance were simplified to the minimum adequate model. We tested the factors block, seeding pattern, species combination, nutrient level, and their interactions. To test between factor levels we used a post-hoc test (Tukey HSD). 
a)

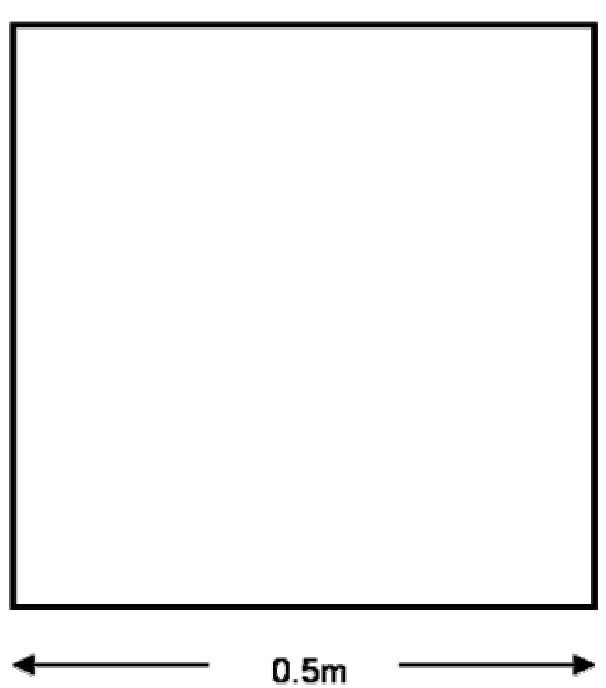

c)

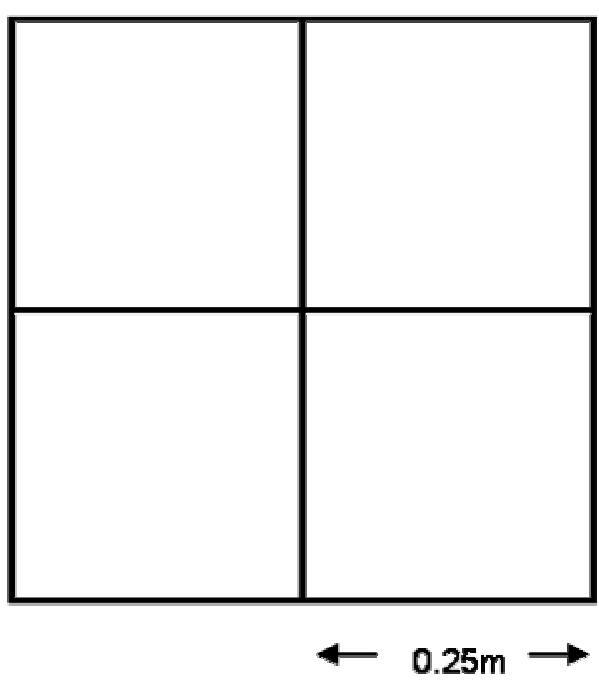

b)

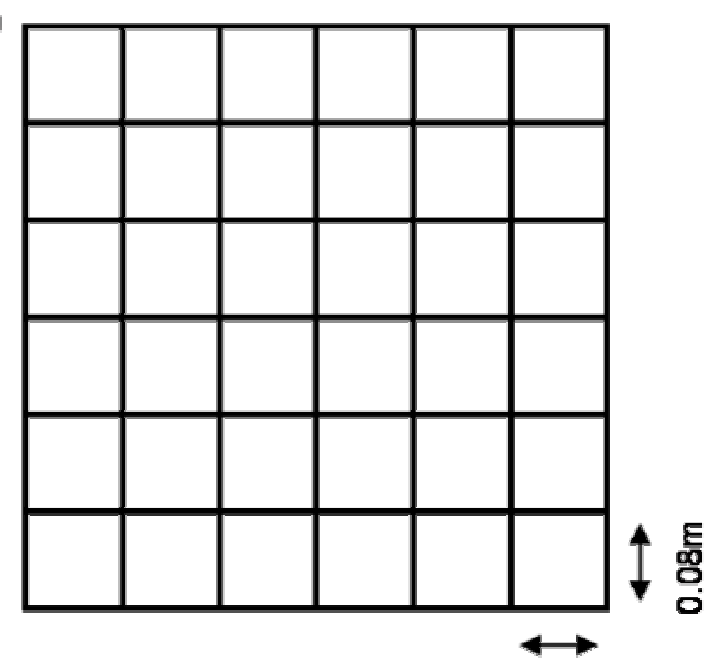

$0.08 \mathrm{~m}$

d)

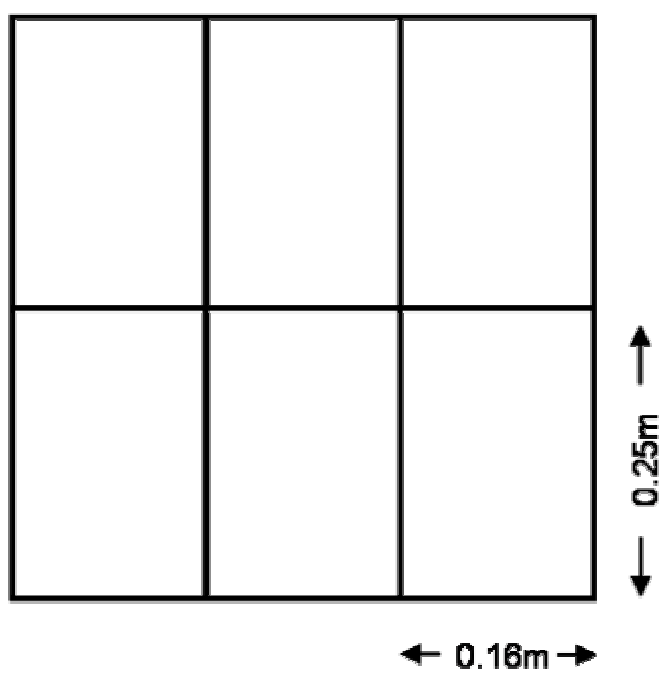

Figure 3.1 Seeding patterns of species mixtures: (a) random dispersal, (b) small scale aggregation, (c) large scale aggregation of four-species mixtures and (d) of two-, and six-species mixtures. 


\section{Results}

\section{Effects of seeding patterns}

Intraspecific aggregation had a strong effect on the biomass of the grass and legume species (Table 3.2). Poa yielded the highest and Bromus yielded the lowest biomass in large scale aggregations. Biomass of Trifolium and Medicago increased significantly with increasing scale of aggregation, yielding the lowest biomass in randomly dispersed plots, more in small scale aggregations and the highest biomass in large scale aggregations (Fig. $3.2)$.

\section{Effects of species combinations in mixtures}

The species composition in mixtures affected the performance of all species (Table 3.2). Biomass of Poa and Bromus was highest in grass-legume mixtures and lowest in grassforb mixtures. Calendula yielded the lowest biomass in forb mixtures and additionally significantly less biomass when cultivated in grass-forb mixtures compared to all-species mixtures. The biomass of Centaurea was lower in forb mixtures than in the all-species mixtures. Trifolium and Medicago, yielded the highest biomass when grown together in the legume mixtures, followed by grass-legume mixtures where they yielded more biomass than in forb-legume mixtures or mixtures with all species (Fig. 3.2).

\section{Effects of nutrient levels}

Poa, Bromus, Calendula, and Centaurea yielded more biomass in nutrient rich plots, for Trifolium and Medicago it was the opposite (Table 3.2, Fig. 3.2). 
Table 3.2 Response of six annual wild plant species to three different seeding patterns (random dispersal, small scale aggregation and large scale aggregation; d. f. = 2), species composition in mixture (grasses, forbs, legumes, grass-forb, legume-forb, forb-legume, and all-species mixtures; d. f. = 3), nutrient level (nutrient poor and nutrient rich; d. f. $=1$ ), and their interactions. ANOVA, $F$ - and $p$-values, ${ }^{*} p<0.05, * * p<0.01, * * * p<0.001$.

\begin{tabular}{|c|c|c|c|c|c|c|c|c|c|c|c|c|}
\hline \multirow[b]{2}{*}{ Biomass per $\mathrm{m}^{2}[\mathrm{~g}]$} & \multicolumn{2}{|c|}{ P. annua } & \multicolumn{2}{|c|}{ B. mollis } & \multicolumn{2}{|c|}{ C. arvensis } & \multicolumn{2}{|c|}{ C. cyanus } & \multicolumn{2}{|c|}{ T. campestre } & \multicolumn{2}{|c|}{ M. lupulina } \\
\hline & $F$ & $p$ & $F$ & $p$ & $F$ & $p$ & $F$ & $p$ & $F$ & $p$ & $F$ & $p$ \\
\hline A: Seeding pattern & 6.96 & $* *$ & 6.51 & $* *$ & & & & & 24.55 & $* * *$ & 33.97 & $* * *$ \\
\hline B: Species composition in mixtures & 2.98 & $*$ & 30.92 & $* * *$ & 26.38 & $* * *$ & 3.83 & $*$ & 21.85 & $* * *$ & 56.88 & $* * *$ \\
\hline C: Nutrient level & 193.29 & $* * *$ & 220.20 & $* * *$ & 141.11 & $* * *$ & 104.66 & $* * *$ & 36.79 & $* * *$ & 4.45 & $*$ \\
\hline D: Block & & & 4.74 & $* *$ & 19.7 & $* * *$ & 6.83 & $* * *$ & & & 11.72 & $* * *$ \\
\hline$A \times B$ & & & 2.81 & $*$ & & & & & & & 9.31 & $* * *$ \\
\hline$A \times C$ & 3.54 & $*$ & 4.2 & $*$ & & & & & 4.72 & $*$ & 7.19 & $* *$ \\
\hline$B \times C$ & 4.76 & $* *$ & 6.81 & $* * *$ & 3.09 & $*$ & & & 8.41 & $* * *$ & 7.05 & $* * *$ \\
\hline
\end{tabular}



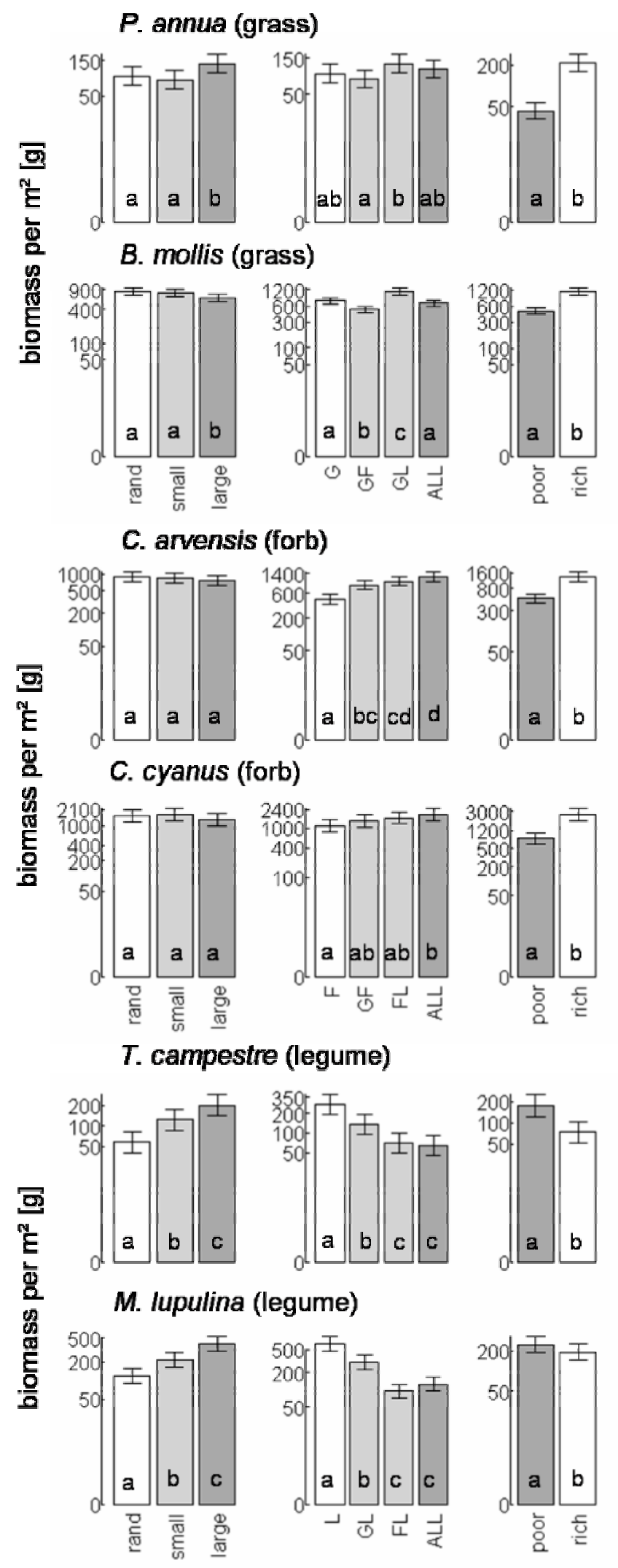

Figure 3.2 Biomass per $\mathrm{m}^{2}$ of six wild plant species cultivated in different seeding patterns (random dispersal, small scale intraspecific aggregation, large scale intraspecific aggregation), different species compositions ( $\mathrm{G}$ - grasses, $\mathrm{F}$ - forbs, $\mathrm{L}$ - legumes, GF - grass-forb mixtures, GL - grass-legume mixtures, FL - forb-legume mixtures, and ALL - all-species mixtures), and in different nutrient levels (nutrient poor, nutrient rich). Mean \pm 1 standard error, note that the y-axes (log transformed) differ. 


\section{Interactions}

Intraspecific aggregation had a varying effect on the biomass of Bromus and Medicago depending on the species composition (interaction A x B, Table 3.2, Fig. 3.3). Bromus yielded the highest biomass in randomly dispersed and small scale aggregations of grasslegume mixtures, while the yield in the grass, grass-forb, and all-species mixtures differed not significantly. Medicago yielded the highest biomass in legume-mixtures and more biomass in large scale aggregations compared to small scale aggregations or random plots of grass-legume and forb-legume mixtures. In all-species mixtures biomass was higher in small and large scale aggregations. The effect of intraspecific aggregation was especially pronounced when species were cultivated in different nutrient levels (interaction A x C, Table 3.2). This was the case for the biomass of Poa, Bromus, Trifolium, and Medicago (Fig. 3.4). Poa yielded significantly more biomass in large scale aggregations in nutrient rich plots. Trifolium and Medicago increased in biomass from random to small scale and further to large scale aggregations in nutrient rich plots. Bromus responded contrary, biomass decreased in large scale aggregations in nutrient poor plots. The effect of the nutrient level varied with the species composition in mixtures for biomass of all species, except Centaurea (interaction B x C, Table 3.2).

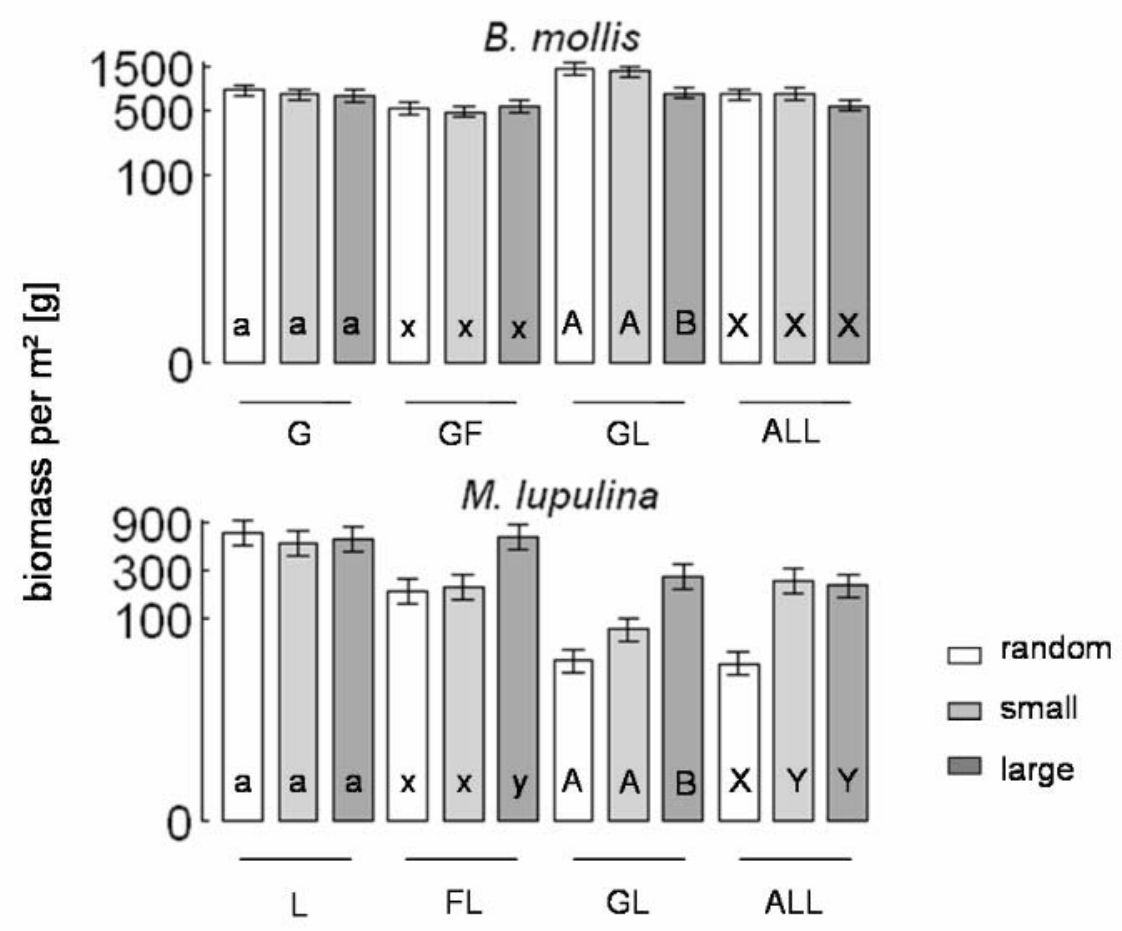

Figure 3.3 Biomass per $\mathrm{m}^{2}$ of wild plant species cultivated in different seeding patterns (random dispersal, small scale intraspecific aggregation, large scale intraspecific aggregation) and species composition ( $\mathrm{G}$ - grasses, L - legumes, GF - grass-forb mixtures, GL - grass-legume mixtures, ALL - all-species mixtures). Mean \pm 1 standard error, interaction seeding pattern $\mathrm{x}$ species composition, ANOVA, Tukey HSD, note that the y-axes (log transformed) differ. 

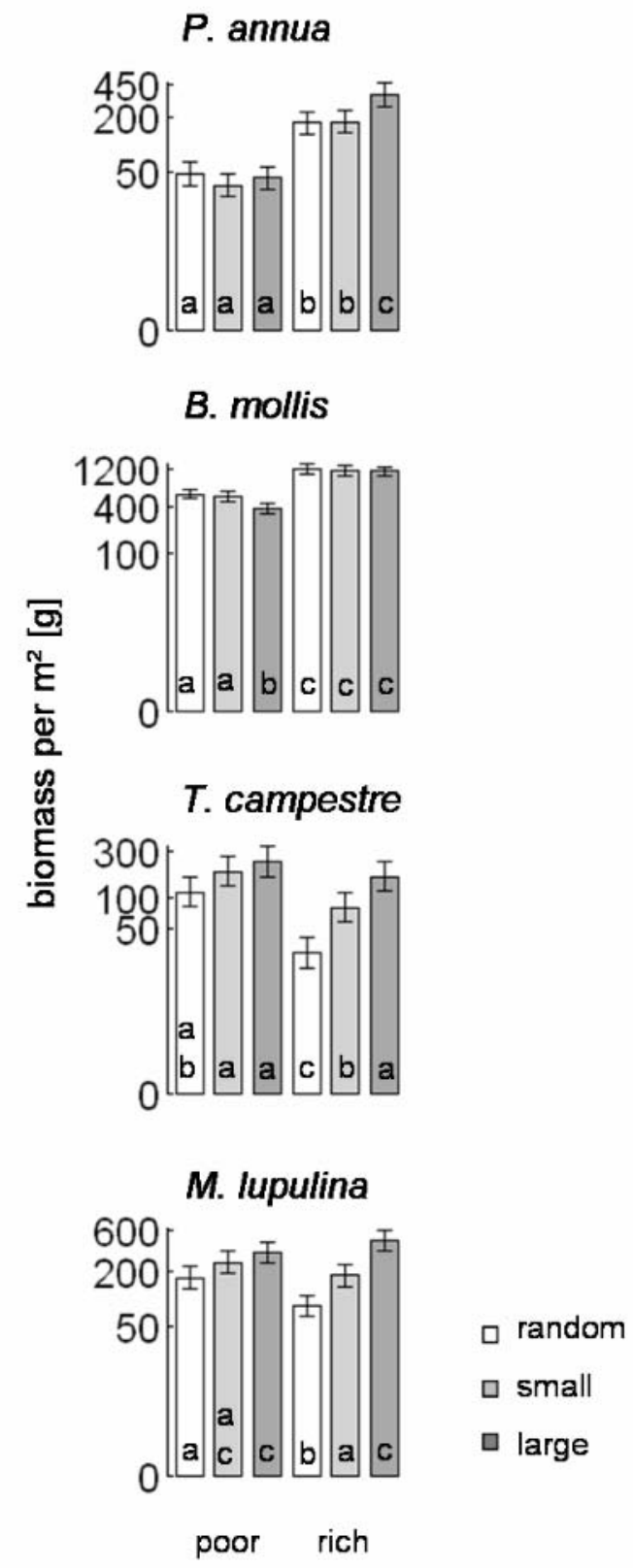

Figure 3.4 Biomass per $\mathrm{m}^{2}$ of wild plant species cultivated in different seeding patterns (random dispersal, small scale intraspecific aggregation, large scale intraspecific aggregation) and nutrient levels (nutrient poor, nutrient rich). Mean \pm 1 standard error, interaction seeding pattern $\mathrm{x}$ nutrient level, ANOVA, Tukey HSD, note that the y-axes (log transformed) differ. 


\section{Discussion}

Our results showed that intraspecific aggregation had a positive effect on the performance of arable wild plant species. Competitively weak species benefited from intraspecific aggregation and increased their performance with increasing scale of intraspecific aggregation. Species composition had also an effect on plant performance. Grasses, but not the forb species were positively affected by the presence of legumes. Nutrient availability determined the performance of all six wild plant species.

The competitively weak species benefited from the shift from the strong interspecific to the less severe intraspecific competition (Amarasekare 2003; Suter et al. 2007; Turnbull et al. 2007). The positive effect was accentuated by the performance of Poa, Trifolium, and Medicago in large scale aggregations. In large scale aggregations more individuals had conspecifics as neighbours, so that interspecific encounters were limited to a relatively small edge area (Chesson and Neuhauser 2002; De Boeck et al. 2006; Mokany et al. 2008). Medicago and Trifolium benefited most from the increasing scale of aggregation, biomass increased already by $25 \%$ and $47 \%$ in small scale aggregations, and by $76 \%$ and $92 \%$ in large scale aggregations. These results indicated that the competitively weak legumes benefited already from the small scale aggregations but were still affected by the remaining interspecific competition. As soon as the scale of intraspecific aggregation increased, their performance increased as well. However, from our experimental set up we do not know whether the performance can be enhanced further by enlarging the scale of aggregation again or whether there is a threshold at which intraspecific competition becomes too strong.

Species composition also influenced the effect of intraspecific aggregations on plant performance. We found interactions between seeding pattern and species composition for the biomass of the grass Bromus and the legume Medicago showing that randomly dispersed diverse species mixtures increase competition for Medicago remarkably. While biomass was highest in the legume mixtures irrespective of the seeding pattern, biomass in all other mixtures was increased in intraspecific aggregations. Contrary, Bromus benefited from the additional nitrogen in small scale aggregations and randomly dispersed plots of the grass-legumes mixtures. Legumes as components in mixtures increased the biomass of both grass species. This result suggests that grasses exploited the additional soil nitrogen better than forbs (Temperton et al. 2007; Roscher et al. 2008). Neighbours of legumes may benefit in two ways. First, by reduced competition for nitrogen since legumes provide their 
own nitrogen and second, additional soil nitrogen allocated via root exudates (Spehn et al. 2002; Temperton et al. 2007). Biomass of the legumes was higher in mixtures containing grasses compared to mixtures with forbs or all species. The results suggested that there might have been a two-sided positive relationship between grasses and legumes on biomass production. In our experiment, the two legumes performed best when grown together, which is contrary to the findings of Temperton et al. (2007), who found that the fitness of a legume species was reduced when it grew next to another legume. Surprisingly, we found no effect of legume species on the forbs. The forbs Calendula and Centaurea responded to the increasing number of species in mixtures but not to the type of competing species and yielded the highest biomass in all-species mixtures. Here, forbs were the most competitive species performing better in randomly dispersed plots and in mixtures with a diverse species composition. This does not support other studies, where (different) forb species were not competitively strong (Sheley and Half 2006; Weigelt et al. 2007) and which found that species composition within in similar species-rich mixtures can explain the variation of aboveground biomass production (Roscher et al. 2008).

As expected, biomass of grasses and forbs was higher in nutrient rich plots, while the legumes Trifolium and Medicago suffered from the high nutrient level and produced less biomass. However, intraspecific aggregation in nutrient rich plots enhanced their biomass production with increasing intraspecific aggregation. Similarly, Poa was enhanced in large scale aggregations. These results illustrate the outstanding importance of intraspecific aggregation for competitively weak plant species as soon as competition becomes more intense as it is the case in nutrient rich plots. Nevertheless, it seemed that the response to nutrient availability was species-specific (Groves et al. 2003). In nutrient rich plots nitrogen was sufficiently available, whereas, in nutrient poor plots plant growth was limited by nitrogen deficiencies. In our experiment, biomass yields of the non-fixing species were highly enhanced in nutrient rich plots. In nutrient rich environments plants compete mainly for light (Lanta and Lepš 2006) and competition for light appears to be more asymmetric than competition for nutrients. Consequently, it is more likely to drive inferior species to extinction (Lepš 1999). Taller plants (here: Calendula and Centaurea) gained from fertilization, whereas shorter plants (here: Poa, Bromus, Trifolium, and Medicago) were suppressed (Lepš 1999). In the long run this will cause competitive exclusion. However, intraspecific aggregation and the shift of competition slowed down these competitive exclusion processes and enabled coexistence. 
In conclusion, the performance of competitively weak arable wild plant species was positively influenced by intraspecific aggregation, and an increased scale of aggregation enhanced plant performance further. Furthermore, the positive effect of intraspecific aggregation was pronounced in nutrient rich plots. Hence, competitively weak species are able to establish and perform well in unfavourable environments such as species rich mixtures and nutrient rich soils as long as they are sown intraspecifically aggregated. Species composition in mixtures affected the plant performance, with grasses benefiting from the legumes. In summary, annually sown field margin strips with intraspecifically aggregated seeding patterns are a simple measure to enhance the performance of competitively weak plant species and increase species-richness in agricultural landscapes, in particular in habitats with a high nutrient availability and therefore strong competition. However, more knowledge and systematic testing of (i) the number of arable wild plant species under variable environmental conditions, (ii) the optimal spatial scale of aggregation and (iii) technical solutions for changed seeding is needed to enhance their coexistence and sustain plant diversity.

\section{Acknowledgements}

We thank Arno Kuhn, Susanne Schiele, Caroline Stannat, Claus Vollhardt, Ines Vollhardt, Christa Waßmuth, Inken Waßmuth, and Hans Erich Waßmuth for their assistance during harvest. 


\section{References}

Aguiar, M.R., Lauenroth, W.K., Peters, D.P., 2001. Intensity of intra- and interspecific competition in coexisting shortgrass species. Journal of Ecology 89, 40-47.

Amarasekare, P., 2003. Competitive coexistence in spatially structured environments: a synthesis. Ecology Letters 6, 1109-1122.

Chesson, P., Neuhauser, C., 2002. Intraspecific aggregation and species coexistence. Trends in Ecology and Evolution 17, 210.

Critchley, C.N.R., 2000. Ecological assessment of plant communities by reference to species traits and habitat preferences. Biodiversity and Conservation 9, 87-105.

Critchley, C.N.R., Fowbert, J.A., 2000. Development of vegetation on set-aside land for up to nine years from a national perspective. Agriculture, Ecosystems and Environment 79, 159-174.

Davies, D.H.K., Carnegie, H.M., 1994. Vegetation patterns and changes in field boundaries and conservation headlands in scottish arable fields. BCPC Monograph 58, 173-184.

De Boeck, H.J., Nijs, I., Lemmens, C.M.H.M., Ceulemans, R., 2006. Underlying effects of spatial aggregation (clumping) in relationships between plant diversity and resource uptake. Oikos 113, 269-278.

De Cauwer, B., Reheul, D., Nijs, I., Milbau, A., 2008. Management of newly established field margins on nutrient-rich soil to reduce weed spread and seed rain into adjacent crops. Weed Research 48, 102-112.

Eggenschwiler, L., Jacot, K.A., Edwards, P.J., 2004. Bedeutung von Samenmischungen und Schnitt für Bunt- und Rotationsbrachen. Natur und Landschaft 79, 544-550.

Freckleton, R.P., Watkinson, A.R., 2000. On detecting and measuring competition in spatially structured plant communities. Ecology Letters 3, 423-432.

Goreaud, F., Loreau, M., Millier, C., 2002. Spatial structure and survival of an inferior competitor: a theoretical model of neighbourhood competition in plants. Ecological Modelling 158, 1-19.

Groves, R.H., Austin, M.P., Kaye, P.E., 2003. Competition between Australian native and introduced grasses along a nutrient gradient. Austral Ecology 28, 491-498.

Gunton, R.M., Kunin, W.E., 2007. Density effects at multiple scales in an experimental plant population. Journal of Ecology 95, 435-445.

Harpole, W.S., Suding, K.N., 2007. Frequency-dependence stabilizes competitive interactions among four annual plants. Ecology Letters 10, 1-6.

Kleijn, D., Sutherland, W.J., 2003. How effective are European agri-environment schemes in conserving and promoting biodiversity? Journal of Applied Ecology 40, 947-969.

Lanta, V., Lepš, J., 2006. Effect of functional group richness and species richness in manipulated productivity-diversity studies: a glasshouse pot experiment. Acta Oecologia 29, 85-96. 
Lawson, C.S., Ford, M.A., Mitchley, J., 2004. The influence of seed addition and cutting regime on the success of grassland restoration on former arable land. Applied Vegetation Science 7, 259-266.

Lepš, J., 1999. Nutrient status, disturbance and competition: an experimental test of relationships in a wet meadow. Journal of Vegetation Science 10, 219-230.

Lepš, J., Brown, V.K., Diaz Len, T.A., Gormsen, D., Hedlund, K., Kailova, J., Korthals, G.W., Mortimer, S.R., Rodriguez-Barruecco, C., Roy, J., Santa Regina, I., van Dijk, C., van der Putten, W.H., 2001. Separating the chance effect from other diversity effects in the functioning of plant communities. Oikos 92, 123-134.

Mokany, K., Ash, J., Roxburgh, S., 2008. Effects of spatial aggregation on competition, complementarity and resource use. Austral Ecology 33, 261-270.

Monzeglio, U., Stoll, P., 2005. Spatial patterns and species performances in experimental plant communities. Oecologia 145, 619-628.

Naeem, S., Knops, J.M.H., Tilmann, D., Howe, K.M., Kennedy, T., Gale, S., 2000. Plant diversity increases resistance to invasion in the absence of covarying extrinsic factors. Oikos 91, 97-108.

Oppermann, R., 2003. Nature balance scheme for farms - evaluation of the ecological situation. Agriculture, Ecosystems and Environment 98, 463-475.

Pakeman, R.J., Pywell, R.F., Wells, T.C.E., 2002. Species spread and persistence: implications for experimental design and habitat re-creation. Applied Vegetation Science 5, 75-86.

Roscher, C., Thein, S., Schmid, B., Scherer-Lorenzen, M., 2008. Complementary nitrogen use among potentially dominant species in a biodiversity experiment varies between two years. Journal of Ecology 96, 477-488.

Sheley, R.L., Half, M.L., 2006. Enhancing native forb establishment and persistence using a rich seed mixture. Restoration Ecology 14, 627-635.

Spehn, E.M., Scherer-Lorenzen, M., Schmid, B., Hector, A., Caldeira, M.C., Dimitrakopoulos, P.G., Finn, J.A., Jumpponen, A., O’Donnovan, G., Pereira, J.S., Schulze, E.-D., Troumbis, A.Y., Körner, C., 2002. The role of legumes as a component of biodiversity in a cross-European study of grassland biomass nitrogen. Oikos 98, 205-218.

Stoate, C., Boatman, N.D., Borralho, R.J., Rio Carvalho, C.R., de Snoo, G.R., Eden, P., 2001. Ecological impacts of arable intensification in Europe. Journal of Environmental Management 63, 337-365.

Stoll, P., Newberry, D.M., 2005. Evidence of species-specific neighborhood effects in the dipterocarpaceae of a bornean rain forest. Ecology 86, 3048-3062.

Stoll, P., Prati, D., 2001. Intraspecific aggregation alters competitive interactions in experimental plant communities. Ecology 82, 319-327.

Stoll, P., Weiner, J., 2000. A neighbourhood view of interactions among individual plants. In: Dieckmann U., Law R., Metz J.A.J. (Eds.). The Geometry of Ecological Interactions: Simplifying Spatial Complexity, Cambridge University Press, Cambridge, pp. 11-27. 
Storkey, J., Westbury, D.B., 2007. Managing arable weeds for biodiversity. Pest Management Science 63, 517-523.

Suter, M., Ramseier, D., Guesewell, S., Connolly, J., 2007. Convergence patterns and multiple species interactions in a designed plant mixture of five species. Oecologia 151, 499-511.

Temperton, V.M., Mwangi, P.N., Scherer-Lorenzen, M., Schmid, B., Buchmann, N., 2007. Positive interactions between nitrogen-fixing legumes and four different neighbouring species in a biodiversity experiment. Oecologia 151, 190-205.

Turnbull, L.A., Coomes, D., Hector, A., Rees, M., 2004. Seed mass and the competition / colonization trade-off: competitive interactions and spatial patterns in a guild of annual plants. Journal of Ecology 92, 97-109.

Turnbull, L.A., Coomes, D.A., Purves, D.W., Rees, M., 2007. How spatial structure alters population and community dynamics in a natural plant community. Journal of Ecology 95, 79-89.

Turnbull, L.A., Rees, M., Crawley, M.J., 1999. Seed mass and the competition/colonization tradeoff: a sowing experiment. Journal of Ecology 87, 899-912.

Weigelt, A., Jolliffe, P., 2003. Indices of plant competition. Journal of Ecology 91, 707-720.

Weigelt, A., Schumacher, J., Walther, T., Bartelheimer, M., Steinlein, T., Beyschlag, W., 2007. Identifying mechanisms of competition in multi-species communities. Journal of Ecology 95, 5364.

Westbury, D.B., Woodcock, B.A., Harris, S.J., Brown, V.K., Potts, S.G., 2008. The effects of seed mix and management on the abundance of desirable and pernicious unsown species in arable buffer strip communities. Weed Research 48, 113-123. 


\section{Chapter 4}

Scale-dependence of intra- and interspecific interactions of annual plants

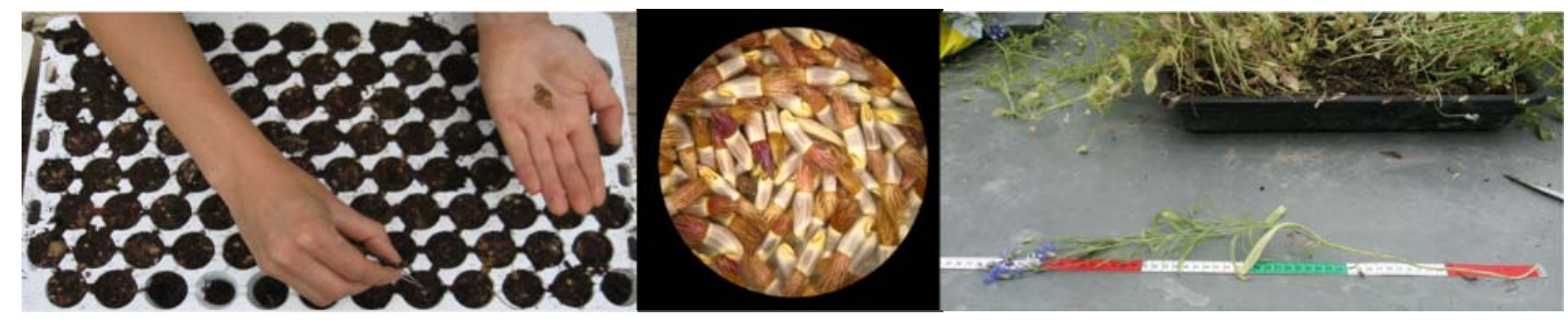

Birte Eleen Waßmuth

Teja Tscharntke Carsten Thies 


\begin{abstract}
Experimental changes of plant community composition can show how plant species differing in competitive ability respond to competitive interactions. Here, we analysed competitive interactions of two annual arable wild plant species, Centaurea cyanus and Viola arvensis, under experimentally aggregated conditions of (i) one, (ii) four, (iii) nine, and (iv) 16 conspecifics, with a distance of $3.5 \mathrm{~cm}$ between plant individuals. The competitively strong $C$. cyanus produced significantly lower biomass, with a trend to lower plant height when grown intraspecifically aggregated. In contrast, the competitively weak $V$. arvensis produced significantly more flowers when grown intraspecifically aggregated. The decreased performance of the competitively strong C. cyanus was detectable at a large scale of interspecific aggregation (16 conspecifics), whereas the increased performance of the competitively weak $V$. arvensis was already detectable at a small scale of interspecific aggregation (four conspecifics). This highlights the species-specific and scale-dependent response in performance in plant communities resulting from intra- and interspecific competition. In conclusion, intraspecific aggregation can reduce the dominance of competitively strong species but more detailed knowledge on species-specific responses between plant species is needed to better understand scale-dependent shifts in the relative importance of intra- and interspecific competition in plant communities.
\end{abstract}

Keywords: annuals; intraspecific and interspecific competition; spatial scale. 


\section{Introduction}

Competition is a crucial process for plant community composition and dynamics. It depends on species identity, number, and distance of neighbouring individuals (Conolly et al. 1990; Molofsky 1999; Stoll and Weiner 2000), this being important for both intraspecific and interspecific competition (Murrel et al. 2001; Rejmánek 2002; Monzeglio and Stoll 2005; Turnbull et al. 2007; Harpole and Suding 2007; Mokany et al. 2008). The relative role of intra- and interspecific interactions therefore can be analysed by two species approaches (Gibson et al. 1999). Plant individuals interact with their closest neighbours (Molofsky 1999; Murell et al. 2001; Milbau et al. 2007), and interactions are more severe the smaller the distance between individuals is (Milbau et al. 2007). Hence, the local competitive neighbourhood is an essential determinant of plant performance (Chesson and Neuhauser 2002; Turnbull et al. 2004). Intraspecific competition appeared to be often more severe than interspecific competition (Chesson 2000; Gustafsson and Ehrlén 2003; Suter et al. 2007; Mokany et al. 2008; but see Naeem et al. 2000; Aguiar et al. 2001; Milbau et al. 2007). Cultivating competitively weak plant species intraspecifically aggregated can therefore enhance their performance (Stoll and Prati 2001; Jumpponen et al. 2005; Monzeglio and Stoll 2005; Mokany et al. 2008). Plants are an important component of biodiversity in ecosystems; hence, the intensity and spatial scales of plant competition may be important for biodiversity, since they influence plant performance.

In this study, we analysed the performance of the two annual plant species $C$. cyanus and $V$. arvensis, which were planted in different spatial scales of intraspecific aggregation. We experimentally established small scale neighbourhoods consisting of (i) one, (ii) four, (iii) nine, or (iv) 16 individuals per species in a total community of 60 individuals per plot. We expected that (1) the performance of the competitively weak $V$. arvensis would be enhanced by intraspecific aggregation and (2) competitive interactions would respond to interspecific aggregation at different spatial scales. 


\section{Materials and Methods}

Centaurea cyanus (L.) and Viola arvensis (Murray) are annual plant species, which are on one side competitively strong (C. cyanus), and on the other side competitively weak ( $V$. arvensis) (Storkey and Cussans 2007; Waßmuth et al. submitted). Both species are characteristic for disturbed agriculturally habitats. We tested intraspecific aggregation at four spatial scales: (a) 1x1 individual per species, (b) 2x2 individuals per species, (c) 3x3 individuals per species, and (d) 4x4 individuals per species resulting in one, four, nine, and 16 conspecific individuals with a constant distance of $3.5 \mathrm{~cm}$ between plant individuals (Fig. 4.1). All treatments were replicated four times and randomly placed in a greenhouse chamber. Seeds were obtained from a commercial supplier (Rieger Hofmann, Blaufelden, Germany) and were sown into multi-pot trays $(3.5 \mathrm{~cm}$ diameter per pot) filled with fertilized garden soil (Fruhstorfer Erde Typ T 25, Archut ${ }^{\circledR}$ Hawita Gruppe, Oldenburg, Germany). After germination individuals of the same size were transplanted $(\sim 4 \mathrm{~cm})$ into trays of $28 \times 45 \times 8 \mathrm{~cm}$. Thirty individuals per species were transplanted per tray at a distance of $3.5 \mathrm{~cm}$. The experiment was carried out over a time span of seven weeks until both species were flowering. At harvest 16 randomly chosen individuals per species were cut at soil level. We counted the numbers of flowers, measured the plant height, and weighed the biomass per individual after a drying period of $48 \mathrm{hrs}$ at $70^{\circ}$ Celsius. Statistical analyses were conducted using the software package R 2.6.2 (http://www.rproject.org). The effect of different spatial scales of aggregation of intraspecific aggregation on the biomass, height, and numbers of flowers were tested using ANOVA. 
a

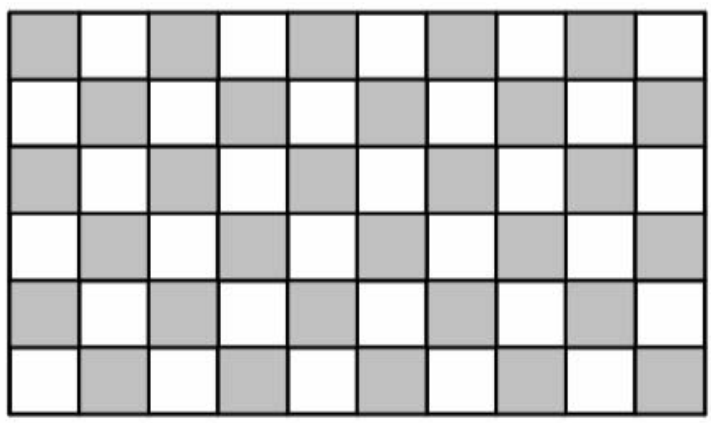

b
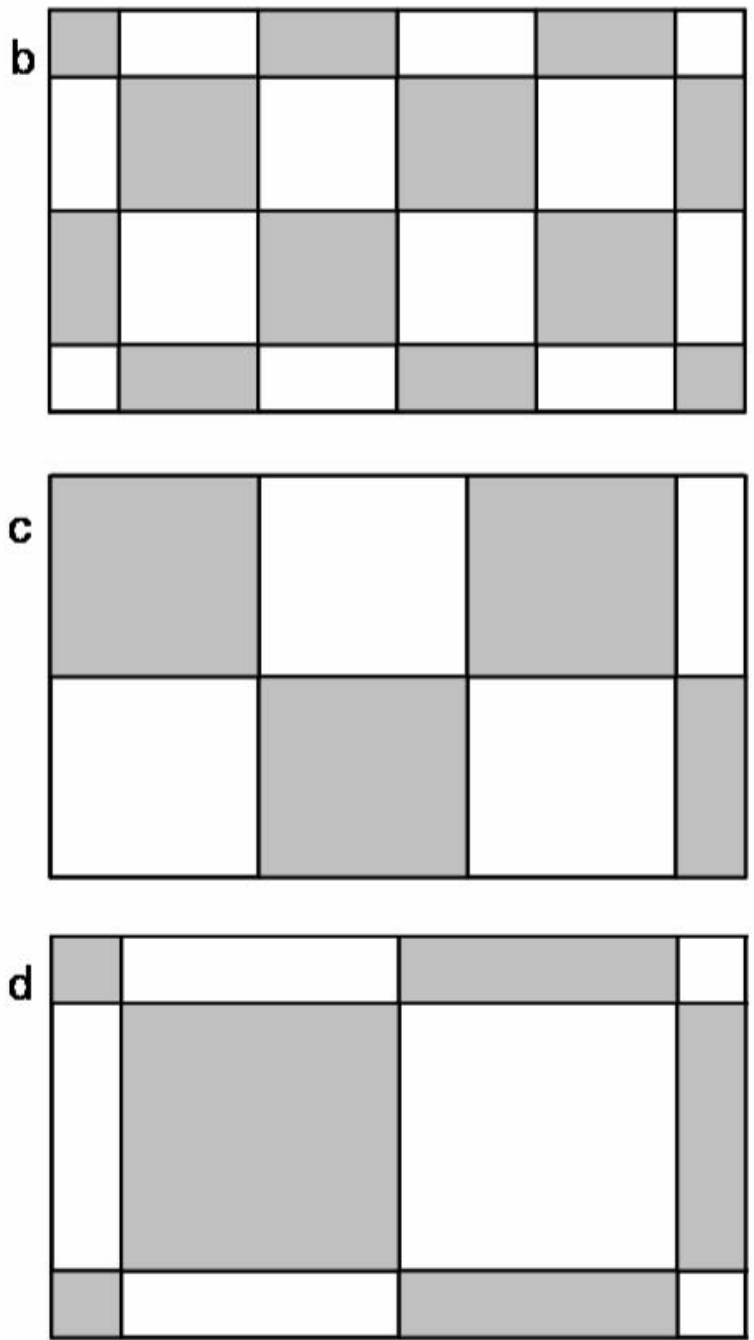

Figure 4.1 Spatial patterns of C. cyanus and V. arvensis individuals planted in four spatial scales of intraspecific aggregation, (a) 1x1individual per species, (b) $2 \times 2$ individuals per species (four conspecifics), (c) $3 \times 3$ individuals per species (nine conspecifics), and (d) $4 \times 4$ individuals per species (16 conspecifics). Distance between planted individuals was $3.5 \mathrm{~cm}$. 


\section{Results}

Biomass of C. cyanus significantly decreased with increasing spatial scale of aggregation $(F=3.52, p=0.049)$, and was $36 \%$ lower at large spatial scales $(4 \times 4$ conspecifics $)$ than at small spatial scales (1x1 individual) (Fig. 4.2). There was also a trend of decreasing plant height with increasing spatial scale of aggregation $(F=2.68, p=0.094)$, whereas the numbers of flowers of $C$. cyanus were not influenced $(F=0.93, p=0.46)$. In contrast, $V$. arvensis significantly increased the number flowers with increasing spatial scale of aggregation $(F=3.53, p=0.045)$, and produced $30-36 \%$ fewer flowers in larger scales of aggregation $(2 \times 2,3 \times 3$, and $4 \times 4$ conspecifics), whereas biomass and plant height of $V$. arvensis did not differ (Fig. 4.2).

(a)

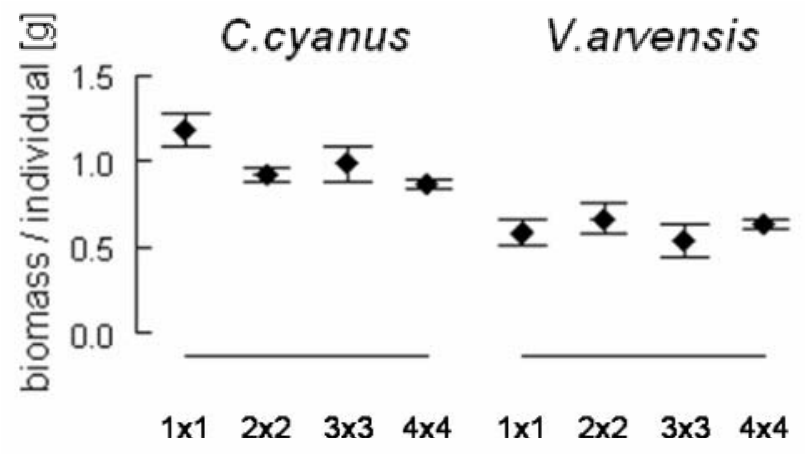

(b)

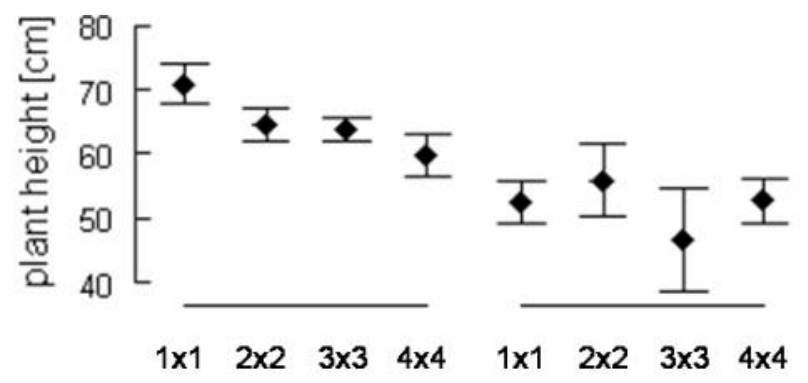

(c)

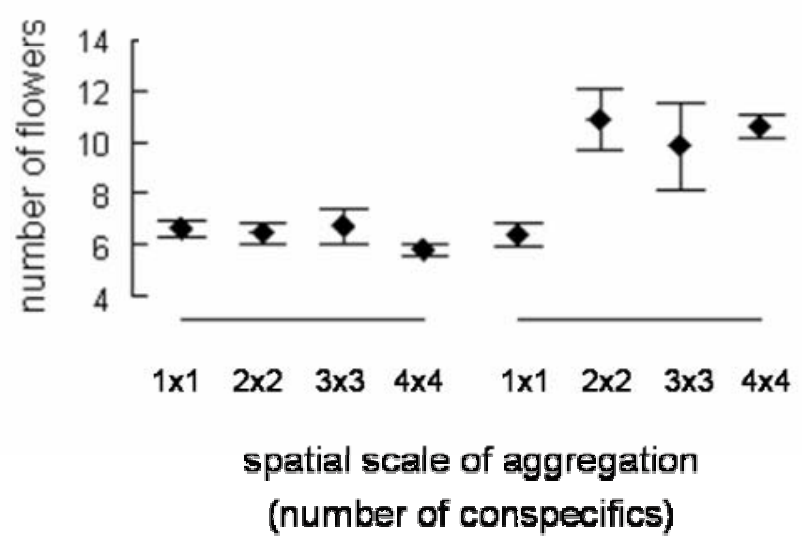

Figure 4.2 Performance of $C$. cyanus and $V$. arvensis individuals planted in four spatial scales of aggregation, (a) biomass per individual $[\mathrm{g}]$, (b) plant height $[\mathrm{cm}]$, and (c) number of flowers per individual. Mean \pm 1 standard error. 


\section{Discussion}

The intraspecific aggregation resulted in significantly lower biomass, with a trend of lower plant height, for the competitively strong C. cyanus, whereas the competitively weak $V$. arvensis produced significantly more flowers. Moreover, these effects were scaledependent, this being important for C. cyanus at the largest spatial scale (16 conspecifics), and for $V$. arvensis at smaller scales (from four conspecifics onwards). Hence, the competitively strong species suffered from increased intraspecific competition, while the competitively weak V. arvensis profited from reduced interspecific competition.

Changes in the performance of plants resulting from the interplay of intra- and interspecific competition are not well understood. Nevertheless, it is intuitively clear and manifoldly shown that competition acts basically among directly neighbouring plants (e.g. Molofsky 1999; Murell et al. 2001; Milbau et al. 2007). In our experimentally homogenised environment the competitively strong $C$. cyanus may have experienced a shift from interspecific to strong intraspecific competition as the spatial scale of intraspecific aggregation increased from 1 to 16 conspecifics. In contrast, the competitively weak $V$. arvensis may have been released from strong interspecific competition as the spatial scale of intraspecific aggregation increased from 1 to 16 conspecifics. Similarly, Stoll and Prati (2001) and Monzeglio and Stoll (2005) described such effects of intraspecific aggregation. However, in our experiment the effects of intra- and interspecific aggregation were scaledependent (Gunton and Kunin 2007). The decreasing performance of the competitively strong species was only detectable at a large spatial scale of interspecific aggregation (16 conspecifics), whereas the enhanced performance of the competitively weak species was already detectable at a small spatial scale of interspecific aggregation (four conspecifics). This underlines the importance of competition between direct neighbours (Stoll and Weiner 2000; Turnbull et al. 2004), but also suggests differences in the spatial scales over which intra- and interspecific competition acts. Therefore, the different spatial scales where competition comes into operation may depend on species composition and their species-specific (relative) competitive ability.

The competitive ability of a species consists of two aspects, the competitive effect and the competitive response or tolerance (Goldberg and Fleetwood 1987). The former is the ability to reduce the performance of other organisms, and the latter is the ability to continue to perform relatively well in the presence of competitors. The competitively strong C. cyanus may exhibit both a strong competitive effect and a high tolerance to other 
individuals, irrespective of their identity. Contrary, the competitively weak $V$. arvensis may exhibit a weak competitive effect but a high tolerance towards conspecifics resulting in an enhanced performance as soon as individuals are intraspecifically aggregated.

In conclusion, changes in the performance of plants resulting from the intra- and interspecific competition may be basically influenced by direct neighbours and their species-specific trait. Important plant traits are plant height, growth form, and seed characteristics in combination with nutrient availability, which can influence the competitive ability among species (Miller and Werner 1987; Leishman 1999; Pywell et al. 2003; Warren and Topping 2004; Fynn et al. 2005; Lanta and Lepš 2007). In addition, our findings make clear that there are scale-dependent shifts in the relative importance of intraund interspecific competition, which have been shown to be species-specific, and therefore to be strongly related to community composition. Scale-dependence may be an important feature for the understanding of competitive interactions in plant communities. 


\section{References}

Aguiar, M.R., Lauenroth, W.K., Peters, D.P., 2001. Intensity of intra- and interspecific competition in coexisting shortgrass species. Journal of Ecology 89, 40-47.

Chesson, P., 2000. Mechanisms of maintenance of species diversity. Annual Review of Ecology and Systematics 31, 343-366.

Chesson, P., Neuhauser, C., 2002. Intraspecific aggregation and species coexistence. Trends in Ecology and Evolution 17, 210.

Conolly, J., Wayne, P., Murray, R., 1990. Time course of plant-plant interactions in experimental mixtures of annuals: density, frequency, and nutrient effects. Oecologia 82, 513-526.

Fynn, R.W.S., Morris, C.D., Kirkham, K.P., 2005. Plant strategies and trait-offs influences trends in competitive ability along gradients of soil fertility and disturbance. Journal of Ecology 93, 384394.

Gibson, D.J., Conolly, J., Hartnett, D.C., Weidenhammer, J.D., 1999. Designs for greenhouse studies of interactions between plants. Journal of Ecology 87, 1-16.

Goldberg, D.E., Fleetwood, L., 1987. Competitive effect and response in four annual plants. The Journal of Ecology 75, 1131-1143.

Gunton, R.M., Kunin, W.E., 2007. Density effects at multiple scales in an experimental plant population. Journal of Ecology 95, 435-445.

Gustafsson, C., Ehrlén, J., 2003. Effects of intraspecific and interspecific density on the demography of a perannial herb, Sanicula europaea. Oikos 100, 317-324.

Harpole, W.S., Suding, K.N., 2007. Frequency-dependence stabilizes competitive interactions among four annual plants. Ecology Letters 10, 1-6.

Jumpponen, A., Mulder, C.P.H., Huss-Danell, K., Högberg, P., 2005. Winners and losers in herbaceous plant communities: insights from foliar carbon isotope composition in monocultures and mixtures. Journal of Ecology 93, 1136-1147.

Lanta, V., Lepš, J., 2007. Effects of species and functional group richness on production in two fertility environments: an experiment with communities of perennial plants. Acta Oecologia 32, 93103.

Leishman, M.R., 1999. How well do plant traits correlate with establishment ability? Evidence from a study of 16 calcareous grassland species. New Phytologist 141, 487-496.

Milbau, A., Reheul, D., De Cauwer, B., Nijs, I., 2007. Factors determining plant-neighbour interactions on different spatial scales in young species-rich grassland communities. Ecological Research 22, 242-247.

Miller, T.E., Werner, P.A., 1987. Competitive effects and responses between plant species in a first-year old-field community. Ecology 68, 1201-1210. 
Mokany, K., Ash, J., Roxburgh, S., 2008. Effects of spatial aggregation on competition, complementarity and resource use. Austral Ecology 33, 261-270.

Molofsky, J., 1999. The effect of nutrients and spacing on neighbor relations in Cardamine pensylvanica. Oikos 84, 506-514.

Monzeglio, U., Stoll, P., 2005. Spatial patterns and species performances in experimental plant communities. Oecologia 145, 619-628.

Murrel, D.J., Purves, D.W., Law, R., 2001. Uniting pattern and process in plant ecology. Trends in Ecology and Evolution 16, 529-530.

Naeem, S., Knops, J.M.H., Tilmann, D., Howe, K.M., Kennedy, T., Gale, S., 2000. Plant diversity increases resistance to invasion in the absence of covarying extrinsic factors. Oikos 91, 97-108.

Pywell, R.F., Bullock, J.M., Roy, D.B., Warman, L., Walker, K.J., Rothery, P., 2003. Plant traits as predictors of performance in ecological restoration. Journal of Applied Ecology 40, 65-77.

Rejmánek, M., 2002. Intraspecific aggregation and coexistence. Trends in Ecology and Evolution $17,209-210$.

Stoll, P., Prati, D., 2001. Intraspecific aggregation alters competitive interactions in experimental plant communities. Ecology 82, 319-327.

Stoll, P., Weiner, J., 2000. A neighbourhood view of interactions among individual plants. In: Dieckmann U., Law R., Metz J.A.J. (Eds.). The Geometry of Ecological Interactions: Simplifying Spatial Complexity, Cambridge University Press, Cambridge, pp. 11-27.

Storkey, J., Cussans, J.W., 2007. Reconciling the conservation of in-field biodiversity with crop production using a simulation model of weed growth and competition. Agriculture, Ecosystems and Environment 122, 173-182.

Suter, M., Ramseier, D., Guesewell, S., Connolly, J., 2007. Convergence patterns and multiple species interactions in a designed plant mixture of five species. Oecologia 151, 499-511.

Turnbull, L.A., Coomes, D., Hector, A., Rees, M., 2004. Seed mass and the competition/colonization trade-off: competitive interactions and spatial patterns in a guild of annual plants. Journal of Ecology 92, 97-109.

Turnbull, L.A., Coomes, D.A., Purves, D.W., Rees, M., 2007. How spatial structure alters population and community dynamics in a natural plant community. Journal of Ecology 95, 79-89.

Warren, J., Topping, C., 2004. A trait specific model of competition in a spatially structured plant community. Ecological Modelling 180, 477-485. 


\section{Chapter 5}

Sowing competitively weak arable wild plant species with intraspecific aggregation helps to enhance coexistence and biodiversity

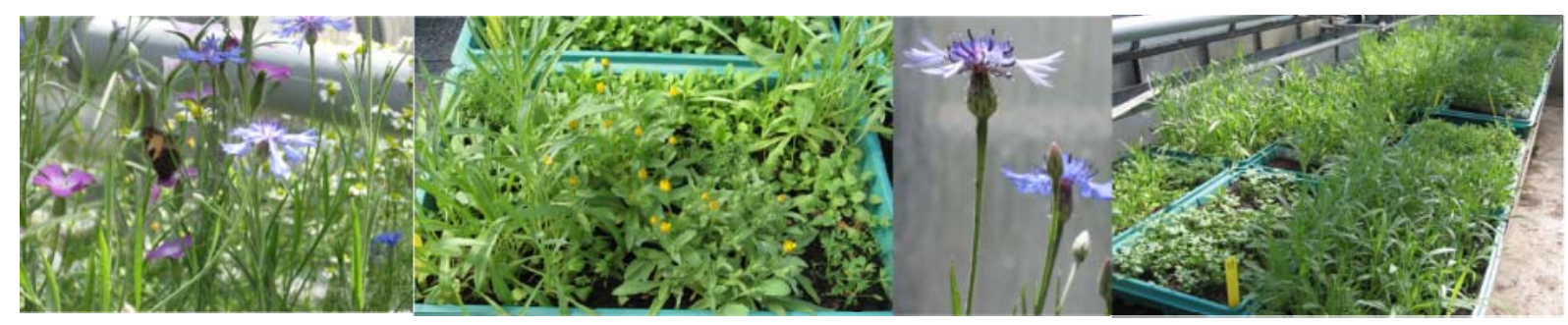

Birte Eleen Waßmuth

Teja Tscharntke Carsten Thies 


\begin{abstract}
Question: Diverse seed mixtures in sown field margin strips often rapidly evolve into species poor communities because of the high competitive ability of few dominant species. In this study, we tested the idea that coexistence of weak competitors can be enhanced by intraspecific aggregation, thereby establishing species-rich communities and enhancing biodiversity.

Location: Göttingen, Lower Saxony, Germany.
\end{abstract}

Methods: We focussed on the performance of annual forbs of arable habitats, which were cultivated in different spatial seeding patterns and seed mixtures.

Results: The performance of most plant species was positively affected by intraspecific aggregation and in particular competitively weak species benefited from intraspecific aggregation. Biomass and the number of individuals were increased in the intraspecifically aggregated seeding pattern, whereas an increasing number of species in mixtures resulted in lower biomass and numbers of individuals in randomly dispersed seed-mixtures.

Conclusion: Intraspecifically aggregated sowings of wild plant species may be a new tool for biodiversity management in agricultural landscapes.

Keywords: annuals; intra- and interspecific competition; margin strips; plant performance; seeding pattern. 


\section{Introduction}

Plant diversity in agricultural habitats has been declining in the last decades due to the intensification of agriculture. Field sizes increased while field boundaries and edges have been removed (Wilson and Aebischer 1995; Kleijn et al. 1998; Critchley and Fowbert 2000). To counteract the threat of endangered annual arable species agri-environment schemes, including incentives for sown field margin strips (BMELV 2007), were set up. However, plant diversity is often very low in field margin strips due to a depleted, speciespoor seed pool and limited seed dispersal from other habitats (Whittingham 2007). Even sowing species rich seed mixtures will not guarantee a diverse plant community, since seedlings may be outcompeted by each other and by common and very competitive plant species from the local seed pool (Zwerger 2002). Establishing diverse plant communities has been shown to be difficult even when seed mixtures are carefully selected (Smith et al. 1994; Bokenstrand et al. 2004; Kiehl et al. 2006). In particular, forbs are known to be harder to establish than grasses due to generally lower competitiveness (Špaéková and Lepš 2001; Sheley and Half 2006).

Competition determines species composition and plant performance depends on the number and identity of neighbours and their distance as several studies have shown (Bergelson 1990; Hitchmough 2000; Turnbull et al. 2004; Stoll and Bergius 2005; Milbau et al. 2007; Wallin et al. 2008). Conspecifics may affect plant individuals relatively more than heterospecifics (Conolly et al. 1990; Amarasekare 2003; Bolker et al. 2003; von Wettberg and Weiner 2004). In monocultures plant individuals experience intense intraspecific competition, while in mixed plant communities there is a shift from intraspecific to interspecific competition depending on community composition and resource availability (Stoll and Prati 2001; Jumpponen et al. 2005; Monzeglio and Stoll 2005). Intraspecific competition is often assumed to be more intense than interspecific competition since individuals of the same species are more likely to share the same resource demands (Aguiar et al. 2001; Warren et al. 2002; Amarasekare 2003; Gustafsson and Ehrlén 2003; Suter et al. 2007; Turnbull et al. 2007; but see Harpole and Suding 2007). Moreover, the response to intraspecific competition may be related to the competitive hierarchy of the species, although most studies on competition have focussed on perennial plant communities (Kleijn et al. 1998; Kirkham et al.1999; Critchley and Fowbert 2000; De Cauwer et al. 2005; Lepš et al. 2007). 
In this study, we analysed annual forb species of a commercially distributed seed mixture (Wildblumenmischung, Rieger-Hofmann, Blaufelden, Germany). We selected a variety of forb species to investigate how spatial seeding patterns determine competition, coexistence and thus diversity of forbs. We focused on the effects of intra- and interspecific competition on the biomass and number of individuals of annual arable forb species. In a greenhouse experiment we analysed (i) two different seeding patterns (intraspecifically aggregated vs. randomly dispersed), and (ii) four different species mixtures (monocultures, 6-species, 9-species, and 12-species mixtures). We expected (1) that the performance of competitively weak species would be enhanced when grown intraspecifically aggregated, and (2) that this effect would be more pronounced in species rich mixtures.

\section{Materials and Methods}

We studied six annual forb species in different species rich mixtures. Study species were Calendula arvensis (L.), Centaurea cyanus (L.), Matricaria recutita (L.), Consolida regalis (Gray), Silene noctiflora (L.), and Viola arvensis (Murray). Additional species in the sown mixtures were Agrostemma githago (L.), Anthemis arvensis (L.), Chrysanthemum segetum (L.), Legouisia speculum-veneris (L.), Myosotis arvensis (L.), and Papaver rhoeas (L.). All species are found in a commercially available seed mixture of flowering arable wild plants (Feldblumenmischung, Rieger-Hofmann GmbH, Blaufelden, Germany). We established (i) two different seeding patterns (intraspecific aggregation and random dispersal of the seeds), and (ii) four seed mixtures with different numbers of species (monocultures, 6-species, 9-species, and 12-species mixtures). In the intraspecific aggregation treatment we divided plastic pots $(0.45 \times 0.28 \times 0.08 \mathrm{~m})$ using a template into nine (9-species mixtures) or twelve subplots (monocultures, 6-species, and 12-species mixtures). Each species occupied one subplot in the 9-species and 12-species mixtures, and two subplots in the 6-species mixtures. Seeding density was 100 seeds per subplot (9528 seeds $/ \mathrm{m})$. Species allocation within subplots was at random. We established four different species mixtures: monocultures of each study species, 6-species mixtures (only our study species), 9-species mixtures (study species + three additional species), and 12-species mixtures (study species + six additional species). Pots were filled with nutrient poor soil (Fruhstorfer Erde Typ Nullerde) and were fertilized twice (1.5 g/pot, $12 \mathrm{~g} / \mathrm{m}^{2}$, ENTEC Blaukorn, $14 \% \mathrm{~N}, 7 \% \mathrm{P}_{2} \mathrm{O}_{5}, 17 \% \mathrm{~K}_{2} \mathrm{O}$ ). All treatments were replicated four times, in total 72 randomly placed pots were established. The experiment ran under natural daylight 
regime in the greenhouse and pots were watered every other day. After eight weeks (July 2006) the number of individuals per species was recorded. Plants were clipped at surface level; aboveground biomass was sorted and dried at $70^{\circ} \mathrm{C}$ for $48 \mathrm{hrs}$. All measured parameters were enumerated to $\mathrm{m}^{2}$ basis. We calculated the competitive ability (CA) following Stoll and Prati (2001) of the study species by dividing the biomass in mixture (random 6-species mixture) by the biomass in monoculture. Species with a CA $>1$ were defined as competitively strong, species with a $\mathrm{CA}<1$ as competitively weak. Data were $\log$ (biomass per $\mathrm{m}^{2}$ ) or square-root transformed (number of individuals) to achieve normality of the residuals. Each study species was analysed separately. Data was analysed by ANOVA and a post-hoc Tukey HSD Test to distinguish between factor levels using the software R (www.r-project.org).

\section{Results}

The competitive abilities (CA) could be ranked in a competitive hierarchy, with Centaurea $(\mathrm{CA}=2.12)$, Calendula $(\mathrm{CA}=1.52)$, and Silene $(\mathrm{CA}=1.22)$ as competitively strong, and Viola $(\mathrm{CA}=0.24)$, Matricaria $(\mathrm{CA}=0.02)$, and Consolida $(\mathrm{CA}=0.01)$ as competitively weak species.

Intraspecific aggregation had a strong effect on the biomass production. Centaurea yielded less biomass per $\mathrm{m}^{2}$, while Viola, Matricaria, and Consolida yielded higher biomass per $\mathrm{m}^{2}$ when cultivated intraspecifically aggregated (Fig. 5.1). Intraspecific aggregation influenced the number of individuals of all species positively (Table 5.1). The number of species in mixtures affected all species, except Silene (Fig. 5.2). Centaurea produced more biomass per $\mathrm{m}^{2}$ in multi-species mixtures and biomass per $\mathrm{m}^{2}$ of Calendula was lower in monocultures than in the 9-species mixtures. The increasing number of species in mixture had a negative effect on the biomass per $\mathrm{m}^{2}$ of Consolida, Matricaria, and Viola. All species yielded more individuals in monocultures than in multi-species mixtures $(p<0.001$ for all species).

The seeding pattern altered the plant performance depending on the number of species in mixture. The biomass per $\mathrm{m}^{2}$ of Viola, Matricaria, and Consolida was lower in randomly dispersed multi-species mixtures (interaction seeding pattern $\mathrm{x}$ number of species in mixture: Viola $F=5.54, p=0.005$; Matricaria $F=6.87, p<0.001$; Consolida $F=8.71, p$ $<0.001$ ). The same was true for the number of individuals of all species (Fig. 5.3). 

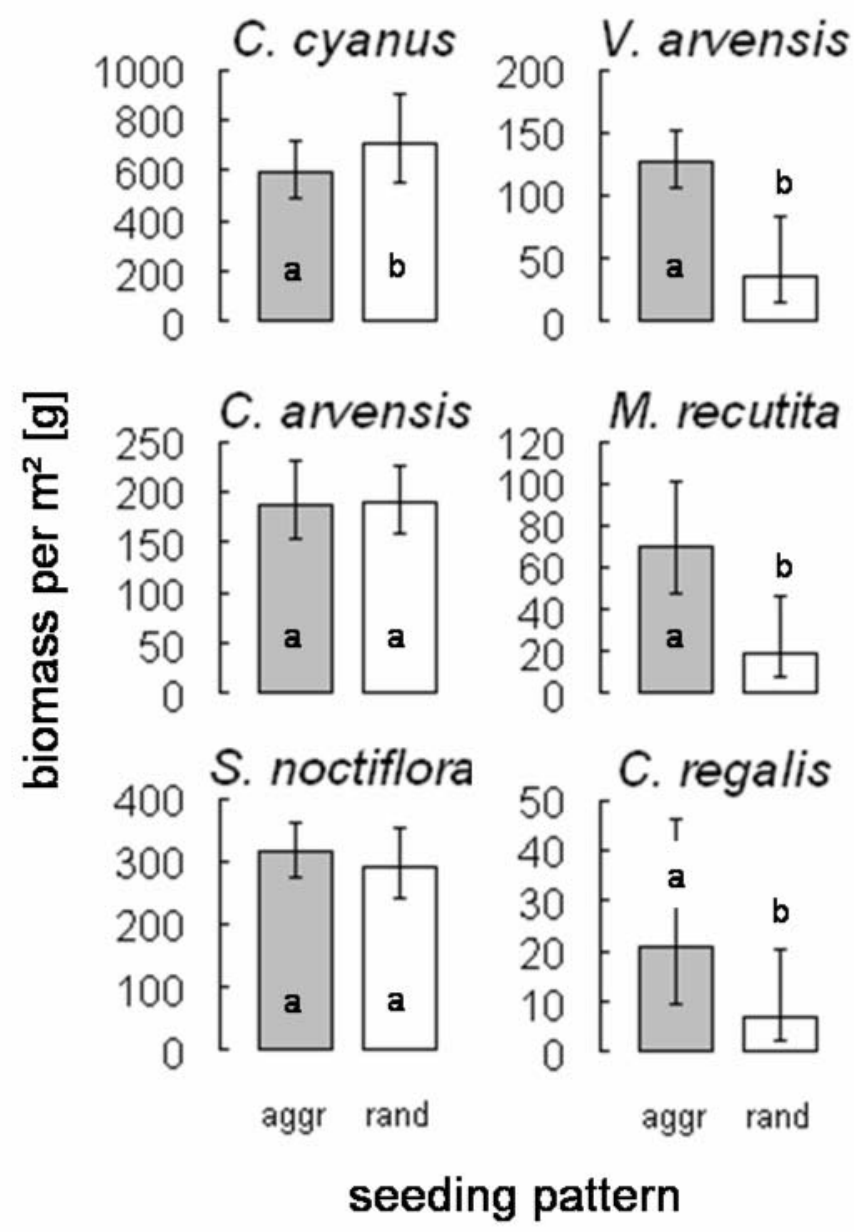

Figure 5.1 Biomass per $\mathrm{m}^{2}[\mathrm{~g}]$ of annual forbs cultivated intraspecifically aggregated (grey bars) and randomly dispersed (white bars). Back-transformed mean values of $\log$ transformed data \pm $95 \%$ confidence intervals, ANOVA. Note the varying y-axis.

Table 5.1 Number of individuals per $\mathrm{m}^{2}$ of six annual forbs cultivated intraspecifically aggregated and randomly dispersed.

\begin{tabular}{|c|c|c|c|c|c|c|}
\hline \multirow[b]{3}{*}{ species } & \multicolumn{6}{|c|}{ number of individuals per $\mathrm{m}^{2}$} \\
\hline & \multicolumn{3}{|c|}{ intraspecific aggregation } & \multicolumn{3}{|c|}{ random dispersal } \\
\hline & mean $\pm 1 \mathrm{SE}$ & $\min$ & $\max$ & mean $\pm 1 \mathrm{SE}$ & $\min$ & $\max$ \\
\hline Centaurea & $1890 \pm 533 \mathrm{a}$ & 768 & 2784 & $672 \pm 821 b$ & 96 & 2208 \\
\hline Calendula & $2766 \pm 361 \mathrm{a}$ & 2112 & 3360 & $768 \pm 899 b$ & 96 & 2688 \\
\hline Silene & $2802 \pm 694 \mathrm{a}$ & 1440 & 3840 & $852 \pm 910 b$ & 96 & 2976 \\
\hline Viola & $2616 \pm 593 a$ & 1623 & 3744 & $816 \pm 1154 b$ & 0 & 3648 \\
\hline Matricaria & $1470 \pm 398 \mathrm{a}$ & 480 & 1920 & $504 \pm 637 b$ & 0 & 1824 \\
\hline Consolida & $624 \pm 359 a$ & 0 & 1248 & $294 \pm 505 b$ & 0 & 1536 \\
\hline
\end{tabular}




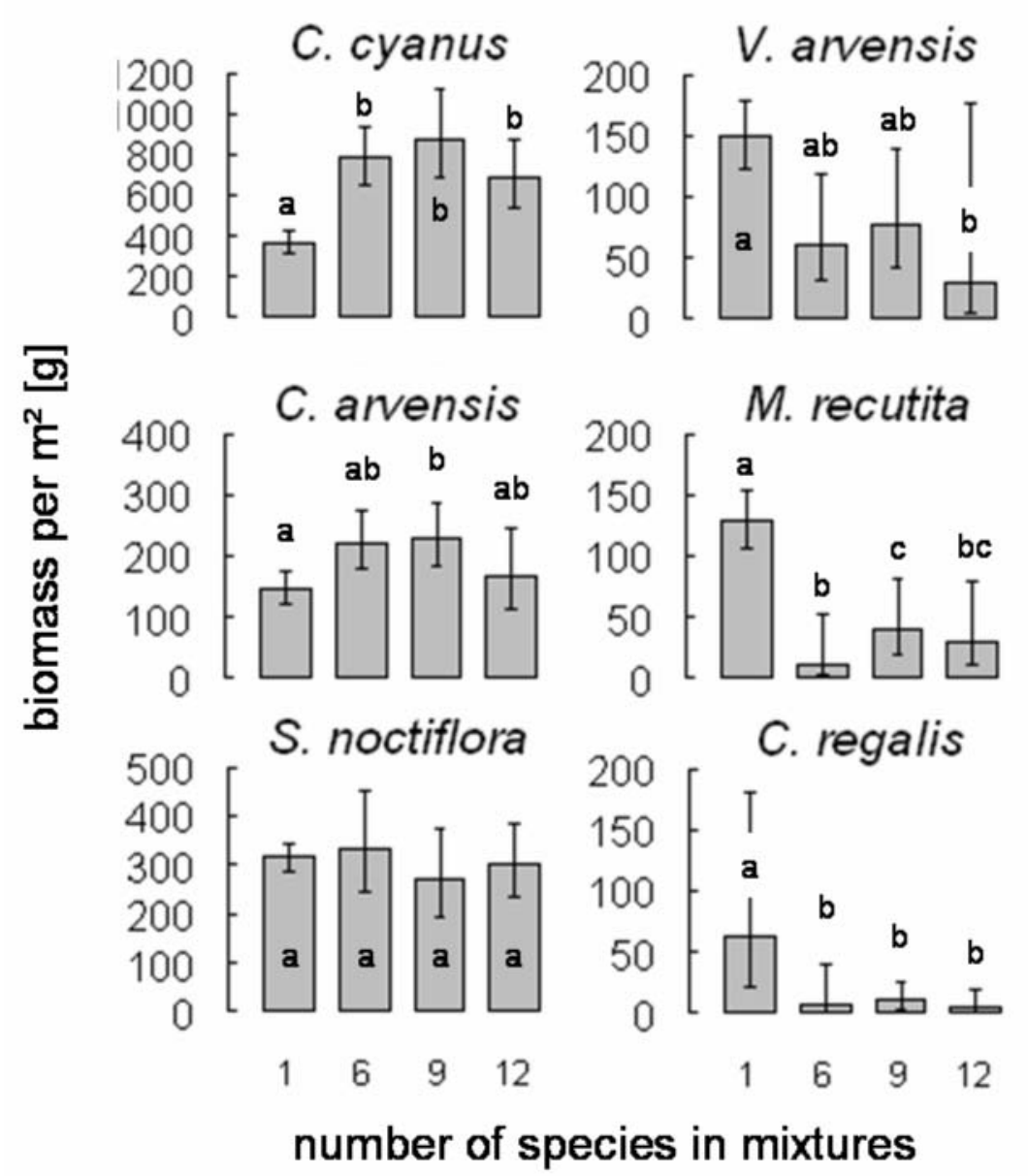

Figure 5.2 Biomass per $\mathrm{m}^{2}[\mathrm{~g}]$ of annual forbs cultivated in monocultures, 6-species, 9-species, and 12 -species mixtures. Back-transformed mean values of $\log$ transformed data $\pm 95 \%$ confidence intervals, ANOVA and TukeyHSD test. Note the varying y-axis. 

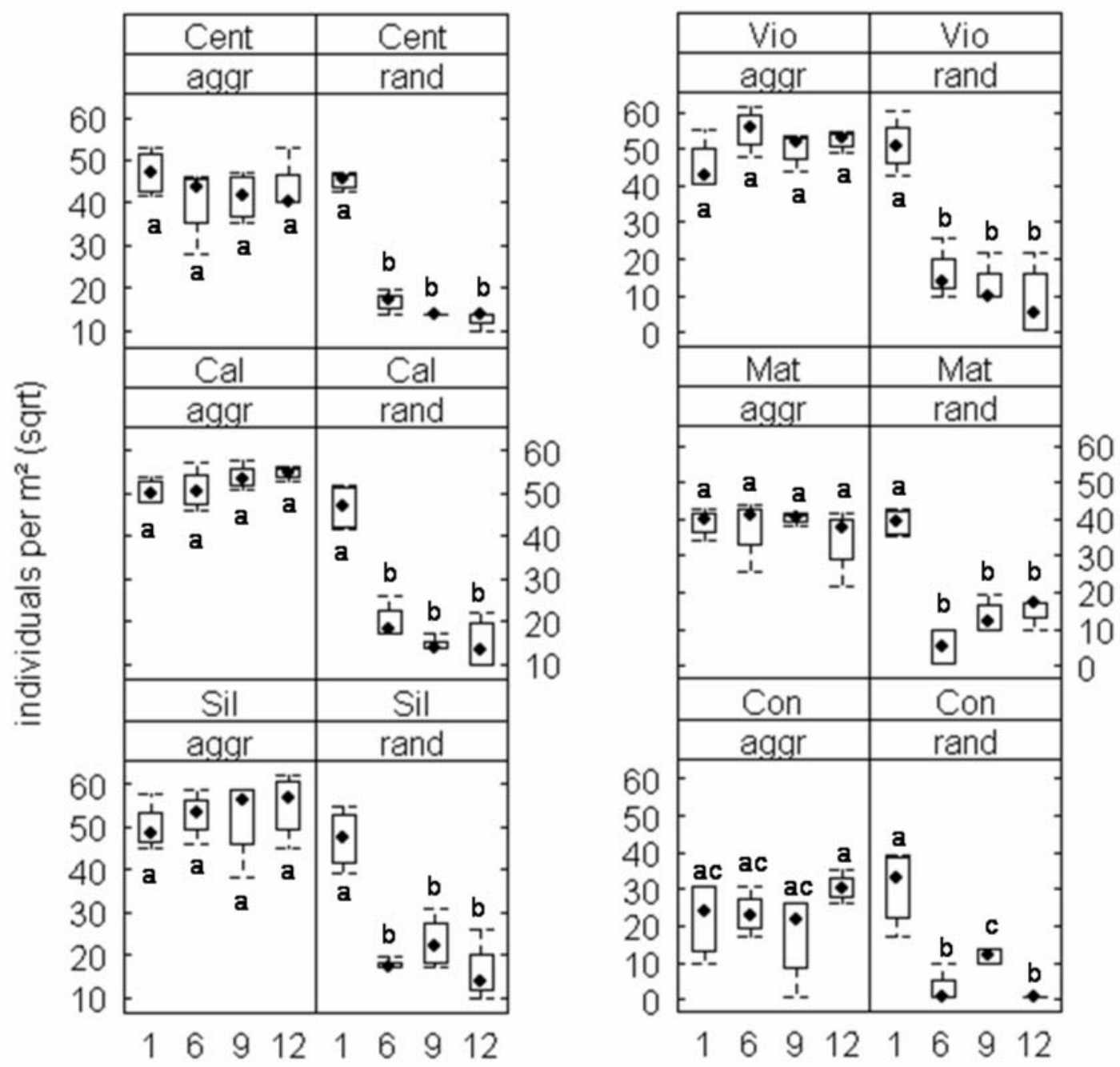

number of species in mixtures

Figure 5.3 Numbers of individuals per $\mathrm{m}^{2}$ of annual forbs cultivated intraspecifically aggregated and randomly dispersed in monocultures, 6-species, 9-species, and 12-species mixtures. Cent $-C$. cyanus, Cal - C. arvensis, Sil $-S$. noctiflora, Vio $-V$. arvensis, Mat $-M$. recutita, Con $-C$. regalis. 


\section{Discussion}

Intraspecific aggregation had a positive effect on plant performance on the competitively weak species. Viola, Matricaria, and Consolida were enhanced in biomass production, whereas the competitively strong species Centaurea was disadvantaged by intraspecific aggregation only in terms of biomass. Competitively strong species yielded more biomass per $\mathrm{m}^{2}$ in multi-species mixtures, while competitively weak species yielded more in monocultures and when cultivated intraspecifically aggregated in multi-species mixtures. Additionally, there was a positive effect of intraspecific aggregation for all species in multi-species mixtures in terms of the number of individuals.

The two most competitive species were Centaurea and Calendula with a CA of 2.12 and 1.52 , respectively. Surprisingly, the commonly so called "noxious weeds" Viola and Matricaria (Albrecht 2005) turned out to be competitively weak in our experiment. This is due to the fact that the competitiveness of each species is relative and depends on the influence of (all) competing species. The competitive hierarchy in a community may change by exchanging just one species (Monzeglio and Stoll 2005; but see Goldberg and Fleetwood 1987). In our experiment, especially Viola, Matricaria, and Consolida were enhanced by intraspecific aggregation in that they produced $\sim 90 \%, \sim 70 \%$, and $\sim 77 \%$ more biomass in intraspecifically aggregated plots. This indicates that the competitively weak species benefited from experiencing less intense intraspecific competition (Chesson 2000; Mokany et al. 2008), while competitively strong species were either negatively (as Centaurea) or not affected (as Calendula and Silene). This negative impact of intraspecific aggregation on competitively strong plants is density dependent (Norris et al. 2001a; Stoll and Prati 2001; Olsen et al. 2005). Remarkably, all species yielded more individuals when cultivated intraspecifically aggregated, although, the increase was not as large for the competitively strong species. The competitively weak species yielded more than three times more individuals in intraspecific aggregation. Hence, competitively weak species benefited twofold from the reduced interspecific competition, since biomass was higher and more seedlings were able to mature. The positive effect of intraspecific aggregation on competitively weak species might persist over a longer time scale, when more individuals of a higher biomass might produce more seeds (Norris et al. 2001b) and add more seeds to the local species pool (Albrecht 2005). 
The number of species in mixture had a negative effect on plant performance. Only the competitively strong Centaurea yielded more biomass per $\mathrm{m}^{2}$ in the multi-species mixtures. Viola, Matricaria, and Consolida suffered from the competition by an increasing number of species and biomass production decreased more than $50 \%$ in the 12 -species mixtures due to relatively higher interspecific competition. Encounters with conspecifics decreased in multi-species mixtures, while encounters with individuals of other species increased (Mokany et al. 2008). Centaurea produced $\sim 48 \%$ more biomass per $\mathrm{m}^{2}$ in 12 species mixtures than in monocultures, which reflects the strong negative impact of intraspecific competition on competitively strong species in monocultures and their ability to suppress weaker species. These results contrast with competition studies that suggest biomass in monocultures as a good predictor of the yield in mixtures (Špaéková and Lepš 2001). In some of the randomly dispersed 12-species mixtures we found no single individual of Viola, Matricaria, and Consolida at harvest. They were outcompeted by interspecific competition, although seedlings established in the beginning. Reducing interspecific encounters in intraspecifically aggregated patches may facilitate diverse mixtures and slow down displacement rates (Levine and Murell 2003), thereby enabling coexistence (Amarasekare 2003).

In conclusion, intraspecific aggregation had a positive effect on plant performance, especially in multi-species mixtures. The number of individuals of all species was higher in all intraspecifically aggregated mixtures and in monocultures. These results should be kept in mind when margin strips are to be established. Sowing annual forbs intraspecifically aggregated will generate species-rich communities, since more individuals of competitively weak plants may establish and propagate, thereby adding seeds to the local species pool. However, further studies especially field experiments are needed because heterogeneous conditions in the field may change competitive interactions and plant performance. Species-rich seed mixtures are only a first step to establish diverse margins. Most important, it further needs intraspecifically aggregated spatial seeding patterns to establish a diverse plant community. Intraspecifically aggregated sowings may be a new tool for biodiversity management in agricultural landscapes.

\section{Acknowledgements}

We thank M. Gollnow, F. Rathing, T. Danell, and M. Schindler for the help with the experiment. 


\section{References}

Aguiar, M.R., Lauenroth, W.K., Peters, D.P., 2001. Intensity of intra- and interspecific competition in coexisting shortgrass species. Journal of Ecology 89, 40-47.

Albrecht, H., 2005. Development of arable weed seedbanks during 6 years after the change from conventional to organic farming. Weed Research 45, 339-350.

Amarasekare, P., 2003. Competitive coexistence in spatially structured environments: a synthesis. Ecology Letters 6, 1109-1122.

Bergelson, J., 1990. Life after death: site pre-emption by remains of Poa annua. Ecology 71, 21572165.

BMELV, 2007. Grundsätze der Förderung einer markt- und standortangepassten Landbewirtschaftung, Berlin.

Bokenstrand, A., Lagerlöf, J., Torstensson, P.R., 2004. Establishment of vegetation in broadened field boundaries in agricultural landscapes. Agriculture, Ecosystems and Environment 101, 21-29.

Bolker, B.M., Pacala, S.W., Neuhauser, C., 2003. Spatial dynamics in model plant communities: what do we really know? American Naturalist 162, 135-148.

Chesson, P., 2000. Mechanisms of maintenance of species diversity. Annual Review of Ecological Systems 31, 343-366.

Conolly, J., Wayne, P., Murray, R., 1990. Time course of plant-plant interactions in experimental mixtures of annuals: density, frequency, and nutrient effects. Oecologia 82, 513-526.

Critchley, C.N.R., Fowbert, J.A., 2000. Development of vegetation on set-aside land for up to nine years from a national perspective. Agriculture, Ecosystems and Environment 79, 159-174.

De Cauwer, B., Reheul, D., D’hooghe, K., Nijs, I., Milbau, A., 2005. Evolution of the vegetation of mown field margins over their first 3 years. Agriculture, Ecosystems and Environment 109, 87-96.

Goldberg, D.E., Fleetwood, L., 1987. Competitive effect and response in four annual plants. Journal of Ecology 75, 1131-1143.

Gustafsson, C., Ehrlén, J., 2003. Effects of intraspecific and interspecific density on the demography of a perennial herb, Sanicula europaea. Oikos 100, 317-324.

Harpole, W.S., Suding, K.N., 2007. Frequency-dependence stabilizes competitive interactions among four annual plants. Ecology Letters 10, 1-6.

Hitchmough, J.D., 2000. Establishment of cultivated herbaceous perennials in purpose-sown native wildflower meadows in south-west Scotland. Landscape and Urban Planning 51, 37-51.

Jumpponen, A., Mulder, C.P.H., Huss-Danell, K., Högberg, P., 2005. Winners and losers in herbaceous plant communities: insights from foliar carbon isotope composition in monocultures and mixtures. Journal of Ecology 93, 1136-1147.

Kiehl, K., Thormann, A., Pfadenhauer, J., 2006. Evaluation of initial restoration measures during the restoration of calcareous grasslands on former arable fields. Restoration Ecology 14, 148-156. 
Kirkham, F.W., Sherwood, A.J., Oakley, J.N., Fielder, A.G., 1999. Botanical composition and invertebrate populations in sown grass and wildflower margins. Aspects of Applied Biology 54, 291-298.

Kleijn, D., Joenje, W., Le Coeur, D., Marshall, E.J.P., 1998. Similarities in vegetation development of newly established herbaceous strips along contrasting European field boundaries. Agriculture, Ecosystems and Environment 68, 13-26.

Lepš, J., Doležal, J., Bezemer, T.M., Brown, V.K., Hedlund, K., Igual Arroyo, M., Jörgensen, H.B., Lawson, C.S., Mortimer, S.R., Peix Geldart, A., Rodiguez Barrueco, C., Santa Regina, I., Šmilauer, P., van der Putten, W.H., 2007. Long-term effectiveness of sowing high and low diversity seed mixtures to enhance plant community development on ex-arable fields. Applied Vegetation Science $10,97-110$.

Levine, J.M., Murrell, D.J., 2003. The community-level consequences of seed dispersal patterns. Annual Review of Ecological Systems 34, 549-574.

Milbau, A., Reheul, D., De Cauwer, B., Nijs, I., 2007. Factors determining plant-neighbour interactions on different spatial scales in young species-rich grassland communities. Ecological Research 22, 242-247.

Mokany, K., Ash, J., Roxburgh, S., 2008. Effects of spatial aggregation on competition, complementarity and resource use. Australian Journal of Ecology 33, 261-270.

Monzeglio, U., Stoll, P., 2005. Spatial patterns and species performances in experimental plant communities. Oecologia 145, 619-628.

Norris, R.F., Elmore, C.L., Rejmánek, M., Akey, W.C., 2001a. Spatial arrangement, density, and competition between barnyardgrass and tomato: I. Crop growth and yield. Weed Science 49, 61-68.

Norris, R.F., Elmore, C.L., Rejmánek, M., Akey, W.C., 2001b. Spatial arrangement, density, and competition between barnyardgrass and tomato: II. Barnyardgrass growth and seed production. Weed Science 49, 69-76.

Olsen, J., Kristensen, L., Weiner, J., Griepentrog, H.W., 2005. Increased density and spatial uniformity increase weed suppression by spring weed. Weed Research 45, 316-321.

Sheley, R.L., Half, M.L., 2006. Enhancing native forb establishment and persistence using a rich seed mixture. Restoration Ecology 14, 627-635.

Smith, H., Feber, R.E., Macdonald, D.W., 1994. The role of wildflower seed mixtures in field margin restoration. BCPC Monograph 58, 289-294.

Špaéková, I., Lepš, J., 2001. Procedure for separating the selection effect from other effects in diversity-productivity relationship. Ecology Letters 4, 585-594.

Stoll, P., Bergius, E., 2005. Pattern and process: competition causes regular spacing of individuals within plant populations. Journal of Ecology 93, 395-403.

Stoll, P., Prati, D., 2001. Intraspecific aggregation alters competitive interactions in experimental plant communities. Ecology 82, 319-327. 
Suter, M., Ramseier, D., Guesewell, S., Connolly, J., 2007. Convergence patterns and multiple species interactions in a designed plant mixture of five species. Oecologia 151, 499-511.

Turnbull, L.A., Coomes, D., Hector, A., Rees, M., 2004. Seed mass and the competition / colonization trade-off: competitive interactions and spatial patterns in a guild of annual plants. Journal of Ecology 92, 97-109.

Turnbull, L.A., Coomes, D.A., Purves, D.W., Rees, M., 2007. How spatial structure alters population and community dynamics in a natural plant community. Journal of Ecology 95, 79-89.

von Wettberg, E., Weiner, J., 2004. Effects of distance to crop rows and to conspecific neighbours on the size of Brassica napus and Veronica persica weeds. Basic and Applied Ecology 5, 35-41.

Wallin, L., Svensson, B.M., Lönn, M., 2007. Artificial dispersal as a restoration tool in meadows: sowing or planting? Restoration Ecology. Doi: 10.11111/j.1526-100X.2007.00350.x.

Warren, J., Wilson, F., Diaz, A., 2002. Competitive relationships in a fertile grassland community does size matter? Oecologia 132, 125-130.

Whittingham, M.J., 2007. Will agri-environment schemes deliver substantial biodiversity gain, and if not why not? Journal of Applied Ecology 44, 1-5.

Wilson, P.J., Aebischer, N.J., 1995. The distribution of dicotyledonous arable weeds in relation to distance from the field edge. Journal of Applied Ecology 32, 295-310.

Zwerger, P., 2002. Bericht aus dem Institut für Unkrautforschung, Braunschweig. Jahresbericht der Biologischen Bundesanstalt für Land- und Forstwirtschaft, 79-84. 


\section{Summary}

Biodiversity in agroecosystems has been declining at an alarming rate. Already in 1982, 15 of the 93 arable wild plant species listed in the German Red Data Book were extinct, which equalled $25 \%$ of all extinct plant species in Germany. In the European Community agrienvironment schemes including incentives to create species-rich field margin strips have been established to improve the conservation of plant communities. However, establishing such communities is often not successful due to a few common and very competitive species. Competition is known to determine the composition of plant communities. Individual plant performance depends on the distance, size, and identity of neighbouring plants. In our experiments, we studied the effect of intra- and interspecific competition on the performance of annual arable wild plant species. We investigated whether a certain spatial seeding pattern, namely intraspecific aggregation, enables competitively weak species to establish and to propagate. Moreover, we studied whether the effect of intraspecific aggregation will change depending on the spatial scale, species combination, and nutrient regime. In the present work, we analysed two field and two pot experiments of varying species mixtures with grasses, forbs and legumes in different combinations and with different treatments.

We showed that intraspecific aggregation had a positive effect on the performance of competitively weak species, irrespective of species identity and experimental setup. Increasing the scale of intraspecific aggregation enhanced especially the biomass production of the legume species Trifolium campestre and Medicago lupulina. Poa annua and Bromus mollis responded to the large scale of aggregation: Poa annua yielded more biomass, while the biomass of Bromus mollis decreased. Moreover, increasing the scale of intraspecific aggregation in a small-scale pot experiment showed that the effects of intraand interspecific competition were species-specific and scale-dependent. The decreasing performance of the competitively strong species was detectable at a large scale of interspecific aggregation, whereas, the enhanced performance of the competitively weak species was already detectable at a small scale of interspecific aggregation. Hence, intraspecific aggregation may already at a small scale of spatial aggregation reduce the dominance of competitively strong species.

Functional group identity of the species in mixtures had a strong effect on the performance of a single species. Grass species were positively affected by the presence of legumes, whereas the forb species did not respond. The performance of legume species was 
enhanced in the only-legumes mixture, but, as soon as grass or forb species appeared as competitors, their biomass decreased due to the higher (interspecific) competition. In contrast, the competitively strong forbs Calendula arvensis and Centaurea cyanus performed better in multi-species mixtures with species of different functional groups, while they were suppressed in the only-forbs mixtures.

Nutrient availability was crucial for the performance of all species. Grass and forb species suffered from nutrient deficiency while the legume species produced relatively more biomass in nutrient poor plots. The positive effect of intraspecific aggregation was most pronounced in nutrient rich plots for the competitively poor legumes. It was as well pronounced in species rich mixtures: In six-species mixtures yielded Medicago lupulina only individuals when cultivated intraspecifically aggregated. Competition in the randomly dispersed plots was so strong that all individuals died until harvest. These results highlight the importance of intraspecific aggregation for plant survival and plant-diversity conservation especially when competition is severe.

In conclusion, we provide strong and experimental evidence that the performance of competitively weak plant species can be enhanced by intraspecific aggregation. Competitively weak and therefore often particularly rare and endangered plant species can better establish and propagate when cultivated intraspecifically aggregated and might, in the long run, establish sustainable populations in the local species pool. Hence, sowings with spatial seeding patterns can successfully contribute to conservation measures by enabling the coexistence of plant species with different competitiveness and thereby, enhance overall plant biodiversity. 


\section{Zusammenfassung}

Die Biodiversität in der Agrarlandschaft hat in den letzten Jahrzehnten stark abgenommen. Bereits 1982 waren 15 der 93 in der Roten Liste aufgeführten Ackerwildpflanzenarten ausgestorben, das entsprach 25\% aller in Deutschland ausgestorbenen Pflanzenarten. Zum Schutz der Ackerwildpflanzen wurden im Rahmen der europäischen Agrarumweltprogramme Ackerrandstreifenprogramme eingerichtet. Hierbei werden Randstreifenansaaten finanziell unterstützt. Allerdings ist die Anlage artenreicher Randstreifen aufgrund einiger weniger, jedoch sehr konkurrenzstarker und somit dominanter Pflanzenarten nicht immer erfolgreich. Die Artenzusammensetzung von Pflanzengesellschaften wird durch die Konkurrenz zwischen verschiedenen Pflanzen bestimmt. Jede einzelne Pflanze wird von ihren Nachbarpflanzen, deren Entfernung, Wuchsform und Artidentität beeinflusst.

In der vorliegenden Arbeit wurde die Auswirkung intra- und interspezifischer Konkurrenz auf einjährige Ackerwildpflanzen untersucht. Es wurde getestet, ob ein räumliches Aussaatmuster - genauer gesagt - die intraspezifische Aggregation (die geklumpte Aussaat bzw. Anordnung von Pflanzen einer Art), die Etablierung konkurrenzschwacher Arten fördern kann. Zusätzlich wurde die Bedeutung und Auswirkung der intraspezifischen Aggregation auf unterschiedlichen räumlichen Ebenen, in verschiedenen Artenzusammensetzungen und bei veränderter Nährstoffversorgung untersucht. In dieser Arbeit werden die Ergebnisse von jeweils zwei Freilandexperimenten und Gewächshausexperimenten vorgestellt. Die Untersuchungen wurden mit unterschiedlichen Ansaaten bestehend aus einjährigen Gräsern, Kräutern und Leguminosen durchgeführt.

Es konnte gezeigt werden, dass die intraspezifische Aggregation konkurrenzschwache Arten unabhängig von der Artidentität und des Versuchsaufbaus positiv beeinflusst. Die Biomasseproduktion der Leguminosen Trifolium campestre und Medicago lupulina stieg bereits bei einer intraspezifischen Aggregation auf einer kleinen räumlichen Skala an; die Aggregation auf einer größeren räumlichen Skala steigerte die Produktivität nochmals signifikant. Poa annua und Bromus mollis reagierten auf die intraspezifische Aggregation auf großer räumlicher Skala: Poa annua produzierte mehr Biomasse, während Bromus mollis weniger produktiv war. Wurden nur wenige Pflanzen in Töpfen unterschiedlich stark intraspezifisch aggregiert, zeigte sich, dass die räumliche Skala auf der intra- und interspezifische Konkurrenz wirkt, artspezifisch ist und zwischen der konkurrenzschwachen und der konkurrenzstarken Art variiert. Bereits die intraspezifische Aggregation von vier Individuen förderte die konkurrenzschwache Art, während die konkurrenzstarke Art erst bei 16 aggregierten Individuen reagierte. 
Die funktionelle Gruppe der Arten in den Ansaaten wirkte sich stark auf die einzelne Art aus. Die angesäten Gräser profitierten von den Leguminosen, während die Kräuter keine Reaktion zeigten. Die Leguminosen waren am erfolgreichsten in der Leguminosenmischung. Sobald Konkurrenz durch Gräser und Kräuter auftrat, nahm die Produktivität durch die verstärkte (interspezifische) Konkurrenz ab. Im Gegensatz dazu produzierten die Kräuter in der Kräutermischung weniger Biomasse und waren in den Mehrartenmischungen mit unterschiedlichen funktionellen Gruppen produktiver.

Die Nährstoffverfügbarkeit beeinflusste alle untersuchten Pflanzenarten unabhängig von ihrer Konkurrenzstärke und ihrer funktionellen Gruppe. Die Gräser und Kräuter produzierten weniger Biomasse bei geringer Nährstoffversorgung, während die Leguminosen in den nährstoffarmen Flächen im Vergleich zu nährstoffreichen Flächen produktiver waren. Die positive Wirkung der intraspezifischen Aggregation auf die konkurrenzschwachen Leguminosen war daher besonders in der nährstoffreichen Variante deutlich zu sehen.

Auch in artenreichen Ansaaten wirkte sich die intraspezifische Aggregation positiv aus. In den aus sechs Ackerwildpflanzenarten bestehenden Ansaaten konnte Medicago lupulina nur bei intraspezifisch aggregierter Aussaat geerntet werden. In der zufälligen Aussaat war die Konkurrenz offensichtlich so hoch, dass alle aufgelaufenen Individuen bis zur Ernte wieder abstarben. Diese Ergebnisse heben die Bedeutung der intraspezifisch aggregierten Aussaat für das Auftreten, Überleben und Vermehren einzelner Ackerwildpflanzenarten und somit für die Etablierung und den Erhalt von artenreichen Pflanzengemeinschaften bei hohem Konkurrenzdruck hervor.

In der vorliegenden Arbeit wurde experimentell der Nachweis erbracht, dass konkurrenzschwache Arten durch intraspezifische Aggregation gefördert werden können. Konkurrenzschwache Pflanzenarten sind häufig seltene und bedrohte Arten. Sie können sich bei intraspezifischer Aggregation besser etablieren und sogar vermehren, wodurch sie langfristig gesehen ein fester Bestandteil des lokalen Artenvorkommens und Samenvorrats werden. Ansaaten mit einem aggregierten Aussaatmuster können daher erfolgreich im Arten- und Naturschutz eingesetzt werden und zum Schutz der Ackerwildpflanzen beitragen. Eine intraspezifische Aggregation ermöglicht die Koexistenz unterschiedlich konkurrenzstarker Pflanzenarten und kann somit die Pflanzendiversität in der Agrarlandschaft erhöhen. 


\section{Danksagung}

Ich bedanke mich herzlich bei Herrn Prof. Dr. Teja Tscharntke für das interessante Thema und die Hilfe bei der Antragstellung. Vielen Dank für die Unterstützung bei der Planung, bei Fachfragen und während der Durchführung meiner Arbeit. Herrn Dr. Carsten Thies danke ich für die Betreuung vor Ort und die vielen hilfreichen Diskussionen über die Vorgehensweise und die Bearbeitung der Manuskripte. Bei Herrn PD Dr. Peter Stoll möchte ich mich herzlich für die Zusammenarbeit, die anregenden Diskussionen in Basel und die Hilfe bei statistischen und versuchstechnischen Fragen bedanken. Vielen Dank für die Übernahme des Korreferats. Ich möchte Herrn Prof. Dr. Isselstein als weiteren Prüfer bei der Disputation danken.

Allen MitarbeiterInnen der Abteilung Agrarökologie vielen Dank für das nette Arbeitsklima und die Hilfe bei allen erdenklichen Fragen. Herzlich bedanken möchte ich mich auch bei Arno, Caro, Claus, Ines und Silke für die Hilfe bei der Versuchsvorbereitung und der Ernte. Besonders danke ich Frau Susanne Schiele für die Unterstützung bei den Versuchen, die hilfreichen Anmerkungen zur Durchführung und ihren „Durchblick“. Herrn Dr. Christoph Scherber danke ich für die statistische Notfallbetreuung und Herrn Friedrich Sundmacher für alle Antworten auf Computerfragen. Ich danke Frau Grabe und Frau Gilles für die Hilfe bei allen Fragen, die die Verwaltung oder Abrechnungen betrafen.

Mein besonderer Dank gilt meiner Familie, die mich tatkräftig unterstützt hat. Danke für die geopferte (Urlaubs-) Zeit, den Einsatz auf der Freifläche in der Feldsaison und die Leihgabe sämtlicher Geräte und Maschinen (Auto, Rasenmäher, Werkzeug, etc.). Vielen Dank für die aufmunternden Worte in den letzten vier Jahren. Ich konnte immer auf eure Unterstützung bauen.

Ebenso bedanke ich mich herzlich bei Harald Keunecke, da er mich immer wieder aufgebaut hat und meine Laune geduldig ertragen hat. Vielen Dank für die Hilfe beim Korrigieren der Texte, der Materialbeschaffung und besonders für die tägliche Motivation. 


\section{Publications}

Waßmuth, B., Stoll, P., Tscharntke, T., Thies, C., (in revision) Spatial aggregation facilitates coexistence and diversity of wild plant species in field margins.

Waßmuth, B., Tscharntke, T., Stoll, P., Thies, C., (in prep.) Increasing the scale of intraspecific aggregation facilitates competitively weak plants.

Waßmuth, B., Tscharntke, T., Thies, C., (submitted) Scale-dependence of intra- and interspecific interactions of annual plants.

Waßmuth, B., Tscharntke, T., Thies, C., (in prep.) Sowing competitively weak arable wild plant species with intraspecific aggregation helps to enhance coexistence and biodiversity.

Waßmuth, B., Stoll, P., Thies, C., Tscharntke, T., 2007. Enhancing coexistence of annual weeds by spatial seeding pattern and changes in species composition and fertilization. Verhandlungen der Gesellschaft für Ökologie 37, 209.

Waßmuth, B., Stoll, P., Tscharntke, T., Thies, C., 2007. Spatial seeding patterns affect competition and coexistence of annual herbs. Proceedings of the 20th Annual Conference of the Section Plant Population Biology of the Ecological Society of Germany, Switzerland and Austria.

Waßmuth, B., Stoll, P., Tscharntke, T., Thies, C., 2006. Intraspecific aggregation of sowing enhances plant coexistence. Proceedings of the 19th Annual Conference of the Section Plant Population Biology of the Ecological Society of Germany, Switzerland and Austria.

Waßmuth, B., Stoll, P., Tscharntke, T., Thies, C., 2006. Intraspecific aggregation of sowing enhances plant coexistence. Verhandlungen der Gesellschaft für Ökologie 36, 406.

Dau, A., Waßmuth, B., Steinmann, H.-H., Gerowitt, B., 2004. Keimung und Entwicklung von Cirsium arvense unter Lichtkonkurrenz - ein Modellversuch. Zeitschrift für Pflanzenkrankheiten und Pflanzenschutz, Sonderheft XIX, 169 -176. 


\section{Curriculum Vitae}

Birte Eleen Waßmuth

born 28.10.1977 in Göttingen

since 09/2004 Phd Studies at the Institute for Agroecology of the Georg-AugustUniversity Göttingen under the supervision of Prof. Dr. Teja Tscharntke, Dr. Carsten Thies and PD Dr. Peter Stoll

05.04 .2004

MSc in Agriculture, Georg-August-University Göttingen

04/2003 - 04/2004 MSc Thesis at the Institute for Plant Pathology and Plant Protection and at the Research Centre for Agriculture and Environment, GeorgAugust-University Göttingen. Entitled: „Keimung und Entwicklung der Ackerkratzdistel (Cirsium arvense (L.) Scop.) bei unterschiedlicher Lichtintensität - ein Modellversuch“

$1998-2004$

Studies in Agricultural Sciences. Concentration: Ressourcenmanagement (Agriculture and Environment), Georg-AugustUniversity Göttingen

08/2002-01/2003 Exchange student at the Swedish Agricultural University SLU, Uppsala, Sweden. Courses in Environmental Protection and Nutrient Cycles

Abitur at the Main-Taunus-Schule, Hofheim / Ts. 